\title{
Modulation of airway and lung tissue mechanics by different intrapulmonary resident gases
}

PhD Thesis

Enikő Erzsébet Lele MD

Department of Medical Physics and Informatics

and

Department of Anaesthesiology and Intensive Therapy

University of Szeged, Hungary

Szeged

2012 


\section{Table of Contents}

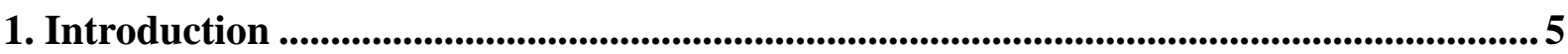

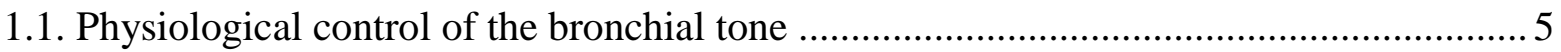

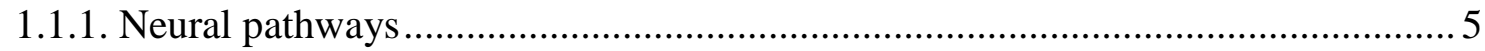

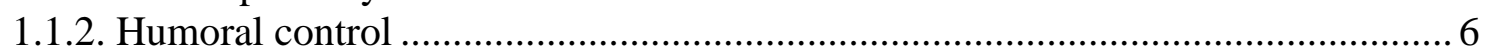

1.1.3. Direct smooth muscle effects …................................................................... 7

1.2. Role of carbon dioxide in regulation of the bronchial tone and in local ventilation distribution

1.3. Effects of volatile anaesthetic agents on lung mechanics ............................................. 9

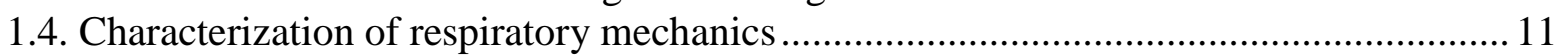

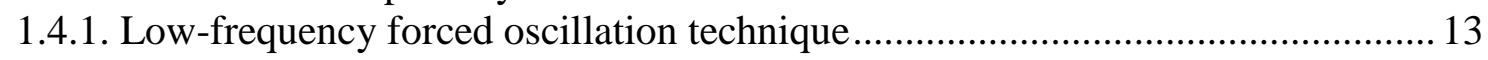

2. Aims of the studies included in the present thesis .....................................................15

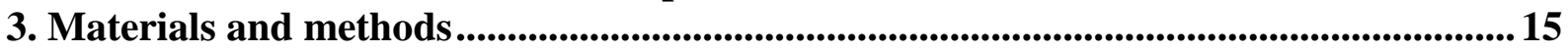

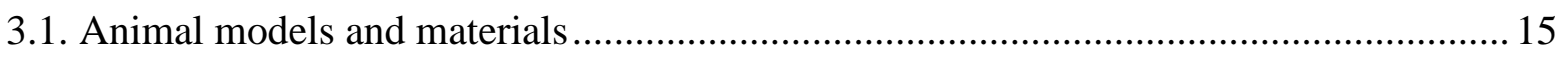

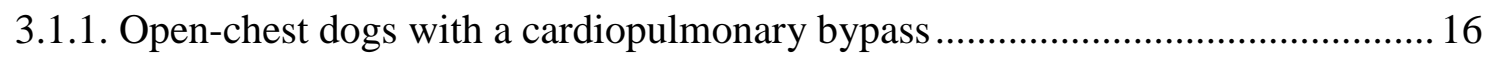

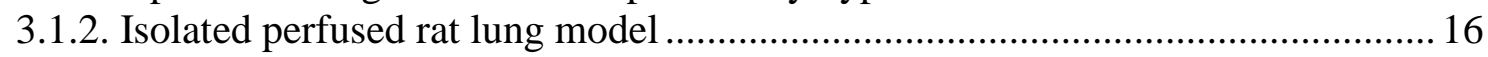

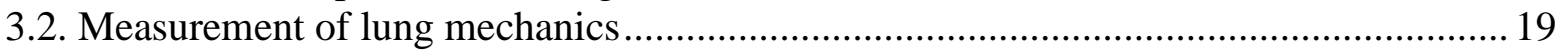

3.2.1. Impedance measurements with the classical set-up in open-chest dogs during

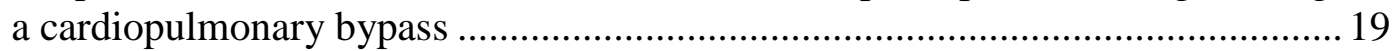

3.2.2. Wave-tube technique in isolated perfused rat lungs ...................................... 20

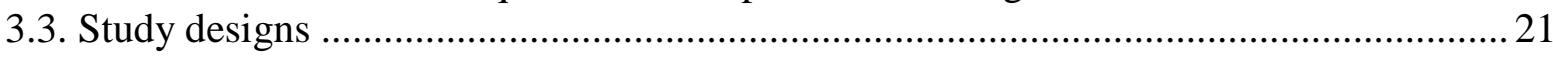

3.3.1. Lung mechanical changes during alveolar hypocapnia and hypercapnia in dogs under a cardiopulmonary bypass .......................................................... 21

3.3.2. Changes in lung mechanics by systemic hypercapnia and acidosis during a cardiopulmonary bypass in an open-chest dog model ......................................... 21

3.3.3. Effects of volatile anaesthetic agents against acetylcholine-induced bronchoconstriction in isolated perfused rat lungs ............................................ 21

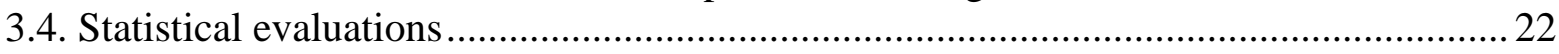

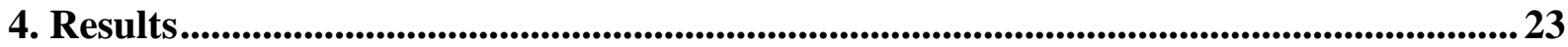

4.1. Alterations in lung mechanics by alveolar hypocapnia and hypercapnia ..................... 23

4.2. Effects of systemic hypercapnia and acidosis on the mechanics of the pulmonary

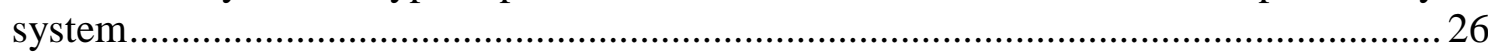

4.3. Effects of volatile anaesthetic agents on the airway and pulmonary parenchymal

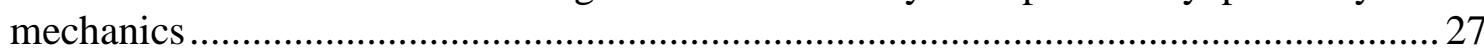

4.4. Prevention of acetylcholine-induced changes in lung mechanics by volatile

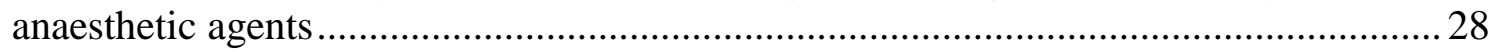

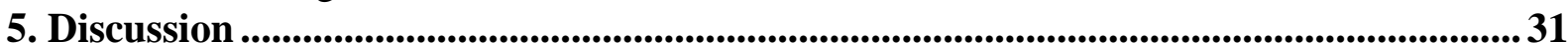

5.1. Effects of alveolar hypocapnia and hypercapnia on the pulmonary mechanics ............. 31

5.2. Changes in the mechanics of the pulmonary system during systemic hypercapnia and

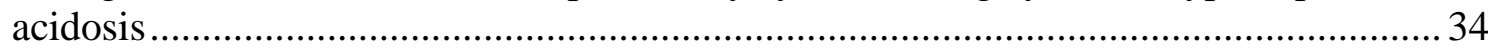

5.3. Effects of volatile anaesthetic agents on the mechanical properties of the lung ............ 35

5.4. Protective potential of volatile anaesthetic agents against acetylcholine-induced

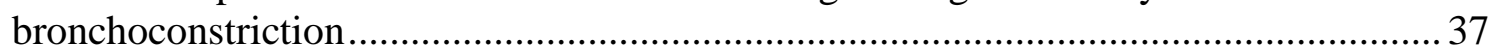

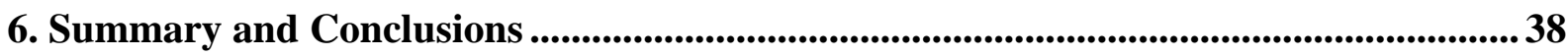

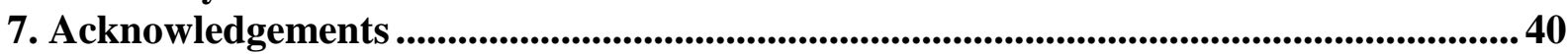

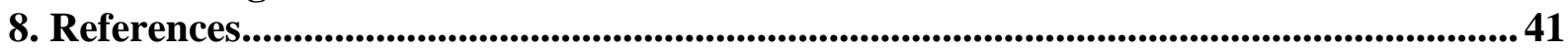




\section{List of papers included in this thesis}

I. Lele E, Petak F, Fontao F, Morel DR, Habre W. Protective effects of volatile agents against acetylcholine-induced bronchoconstriction in isolated perfused rat lungs. Acta Anaesthesiologica Scandinavica. 2006; 50: 1145-1151.

II. Lele EE, Hantos Z, Bitay M, Szívós B, Bogáts G, Peták F, Babik B. Bronchoconstriction during alveolar hypocapnia and systemic hypercapnia in dogs with a cardiopulmonary bypass. Respiratory Physiology \& Neurobiology. 2011; 175: 140-145.

\section{List of papers related to the subject of this thesis}

I. Habre W, Peták F, Ruchonnet-Metrailler I, Donati Y, Tolsa JF, Lele E, Albu G, Beghetti M, Barazzone-Argiroffo C. The role of endothelin-1 in hyperoxia-induced lung injury in mice. Respiratory Research. 2006; 7: 45.

II. Habre W, Adamicza A, Lele E, Novák T, Sly PD, Petak F. The involvement of histaminic and muscarinic receptors in the bronchoconstriction induced by myorelaxant administration in sensitized rabbits. Anesthesia \& Analgesia. 2008; 107: 1899-1906.

III. Peták F, Albu G, Lele E, Hantos Z, Morel DR, Fontao F, Habre W. Lung mechanical and vascular changes during positive- and negative-pressure lung inflations: importance of reference pressures in the pulmonary vasculature. Journal of Applied Physiology. 2009; 106: $935-42$. 


\section{Figures}

Figure 1. Experimental set-up for the isolated perfused lung model.

Figure 2. Set-up for open-chest dogs during a cardiopulmonary bypass.

Figure 3. Schematic illustration of the experimental protocol employed in isolated perfused rat lungs.

Figure 4. Frequency dependence of pulmonary input impedance. Representative measurements of pulmonary resistance and reactance as functions of frequency in open-chest dogs during a cardiopulmonary bypass.

Figure 5. Effects of $\mathrm{Fi}_{\mathrm{CO}_{2}}$ on airway and lung tissue mechanical parameters of individual animals during a cardiopulmonary bypass.

Figure 6. Changes caused by alveolar hypocapnia and hypercapnia in lung mechanics in open-chest dogs during a cardiopulmonary bypass.

Figure 7. Changes caused by systemic acidosis and following administration of atropine in pulmonary mechanical properties.

Figure 8. Changes caused by volatile anaesthetic agents in mechanical properties of isolated perfused rat lungs.

Figure 9. Protective effects of volatile anaesthetic agents against acetylcholine-induced bronchoconstriction in isolated perfused rat lungs.

Figure 10. Changes in airway smooth muscle tone in isolated perfused rat lungs between different conditions (i.e. with and without volatile anaesthetics) following the administration of two different concentrations of acetylcholine.

Figure 11. Changes in the mechanical properties of the pulmonary tissue in isolated perfused rat lungs between different conditions (i.e. with and without volatile anaesthetics) following the administration of two different concentrations of acetylcholine. 


\section{Glossary of terms}

$\alpha \quad$ exponent of angular frequency in constant-phase tissue model

$\gamma \quad$ complex propagation wave number of wave-tube

$\eta \quad$ tissue hysteresivity

$\boldsymbol{\varphi} \quad$ phase angle

$\omega$ angular frequency

ACh acetylcholine

$\mathrm{CO}_{2}$ carbon dioxide

CPB cardiopulmonary bypass

f frequency

FOT forced oscillation technique

$\mathbf{F i}_{\mathrm{CO}_{2}}$ fraction of inspired carbon dioxide

G constant-phase tissue damping

H constant-phase tissue elastance

I $_{\text {aw }}$ airway inertance

ID internal diameter

ip intraperitoneal(ly)

iv intravenous(ly)

j imaginary unit

$\mathbf{K}_{\text {ATP }}$ ischaemic $\mathrm{K}^{+}$channel

L length of wave-tube

MCh methacholine

MAC minimum alveolar concentration

$\mathbf{P}_{1} \quad$ pressure at loudspeaker end of wave-tube
$\mathbf{P}_{2}$ pressure at distal end of wave-tube

$\mathbf{P}_{\text {aw }}$ airway pressure

$\mathbf{P a}_{\mathrm{O}_{2}}$ arterial partial pressure of oxygen

$\mathbf{P a}_{\mathrm{CO}_{2}}$ arterial partial pressure of carbon dioxide

PEEP positive end-expiratory pressure

$\mathbf{P E T}_{\mathrm{CO}_{2}}$ end-tidal partial pressure of carbon dioxide

$\mathbf{P}_{\mathbf{l a}} \quad$ left atrial pressure

$\mathbf{P}_{\text {pa }} \quad$ pulmonary arterial pressure

$\mathbf{P}_{\text {tr }}$ transrespiratory pressure

$\mathbf{Q}_{\mathbf{p}} \quad$ pulmonary blood flow

$\mathbf{R}_{\text {aw }}$ airway resistance

$\mathbf{R}_{\text {int }}$ pulmonary interrupter resistance

$\mathbf{R}_{\mathbf{L}}$ pulmonary resistance

$\mathbf{R}_{\mathrm{rs}}$ respiratory resistance

$\mathbf{R}_{\mathbf{v}} \quad$ pulmonary vascular resistance

SE standard error

V' airflow

$\mathbf{X}_{\mathbf{L}}$ pulmonary reactance

$\mathbf{X}_{\mathrm{rs}}$ respiratory reactance

$\mathbf{Z}_{\mathbf{0}} \quad$ characteristic impedance of wave-tube

$\mathbf{Z}_{\mathbf{L}} \quad$ pulmonary input impedance

$\mathbf{Z}_{\text {rs }} \quad$ respiratory input impedance 


\section{Introduction}

Patients under general anaesthesia are subjected to continuous physiological monitoring to allow the control of safe induction, the maintenance of general anaesthesia and the prevention and management of emergency situations. To ensure safety, anaesthesia practitioners must possess a solid theoretical knowledge of the physiological and pathophysiological mechanisms of the neurohumoral regulation of the respiratory system and the bronchial motor tone. They must acquire a comprehensive and intricate knowledge of the use of various medical gases, anaesthetic agents and vapours, and medical breathing circuits. The measurement and monitoring of anaesthetic gases, such as oxygen, nitrous oxide, carbon dioxide $\left(\mathrm{CO}_{2}\right)$ and inhalational anaesthetics are mandatory for day-to-day anaesthesia practice.

\subsection{Physiological control of the bronchial tone}

Along the tracheobronchial tree, the zone including the bronchioles has the strongest muscular bands and consequently these regions are the main target of physiological regulatory mechanisms or regional lung ventilation ${ }^{1}$. Contraction of these helical bands can decrease the diameter of the bronchioles, wrinkle the mucosa into varying numbers of longitudinal folds and result in an elevated airway resistance.

\subsubsection{Neural pathways}

The physiological bronchial tone is regulated in part by neurohumoral mechanisms. The innervations of the airways are supplied by the autonomic nervous system. The parasympathetic cholinergic vagus nerve constitutes the predominant neural bronchoconstrictor system that serves an important role in regulation of the airway tone. Afferent and efferent fibres travel in the vagus nerve with efferent ganglia in the walls of the small bronchi. There are two classes of afferent nerve fibres: myelinated, rapidly adapting strech receptors and non-myelinated C-fibres. Efferent postganglionic cholinergic fibres, from the vagal motor nuclei of the brainstem via the vagus nerve to the parasympathetic ganglia (located within the bronchial wall) ${ }^{2,3}$ and over the peribronchial plexus (all the way down to the level of small bronchi), innervate the airway smooth muscle and the submucosal glands. The density of the innervations diminishes from the trachea to the terminal bronchioles, there 
is no further innervation of the airway epithelium and the alveoli in humans ${ }^{4,5}$. The acetylcholine $(\mathrm{ACh})$ released from the preganglionic and postganglionic nerve fibres acts on the target cells through three types of muscarinic receptor: $\mathrm{M}_{1}, \mathrm{M}_{2}$, and $\mathrm{M}_{3}$, which modulate the bronchial airway and vascular smooth muscle tone ${ }^{6}$. Direct physical stimulation, such as a suction manoeuvre, laryngoscopy, inhalation of dust or cold air, or direct chemical stimuli, such as gastric acids at low $\mathrm{pH}$, can activate parasympathetic reflexes, causing bronchoconstriction.

Ultrastructural studies on humans have revealed adrenergic postganglionic sympathetic nerve fibres in the pulmonary vascular smooth muscle, in close proximity to submucosal glands, and airway ganglia, but they are not present in airway smooth muscle ${ }^{7}$. However, despite the lack of sympathetic innervation, the diffusion of the sympathetic postganglionic neurotransmitter norepinephrine to the parasympathetic ganglia or directly to the airway smooth muscle can inhibit airway constriction.

The airways are also regulated by a third form of autonomic control that is neither adrenergic nor cholinergic (NANC system). This NANC nervous system can exert either an excitatory function with the neurotransmitter substance $\mathrm{P}$ and neurokinin $\mathrm{A}$, causing bronchoconstriction (e-NANC system), or an inhibitory function with the neurotransmitter neuropeptide $\mathrm{Y}$, resulting in bronchodilatation (i-NANC system) ${ }^{8}$.

\subsubsection{Humoral control}

Despite the lack of real anatomic sympathetic innervation, the bronchial smooth muscle possesses a high number of $\beta_{2}$-receptors that are sensitive to circulating adrenaline. Activation of the $\beta_{2}$-receptors increases the cAMP level, thereby lowering the $\mathrm{Ca}^{2+}$ influx into the airway smooth muscle cells, which results in bronchodilation. Under physiological circumstances, the basal levels of adrenaline do not modify the bronchial muscle tone, but this mechanism is of significance in the presence of an elevated muscle tone, such as that which develops during exercise or stress.

$\alpha$-adrenoreceptors are situated in pulmonary and bronchial blood vessels, the bronchial epithelial cell membrane, and also on submucosal glands, in parasympathetic ganglia, and on cholinergic and $\mathrm{C}$ afferent nerve fibres ${ }^{3}$. In vitro studies have demonstrated that $\alpha_{2}$-adrenergic stimulation increases mucus secretion and induces smooth muscle contraction ${ }^{9}$. However, this 
effect can be detected only in preconstricted healthy airway smooth muscle, in humans and dogs, or in tissue samples originating from diseased human lungs ${ }^{9}$. In vivo, $\alpha_{2}$-adrenergic stimulation has no effect on the bronchomotor tone in healthy individuals, but might induce bronchoconstriction in asthmatic patients ${ }^{10,11}$.

\subsubsection{Direct smooth muscle effects}

Some substances are able to affect the tone of the airway smooth muscle directly. Decreased levels of the arterial partial pressure of carbon dioxide $\left(\mathrm{Pa}_{\mathrm{CO}_{2}}\right)$, histamine, $\mathrm{ACh}$, thromboxane $\mathrm{A}_{2}$ and leukotrienes $\mathrm{C}_{4}$ tend to cause direct airway smooth muscle contraction.

Besides these regulatory mechanisms, varying concentrations of physiological or anaesthesiological resident gases in the pulmonary system may also affect the different neurohumoral mechanisms that regulate and modulate the bronchial tone; these pathways, however, have not been fully characterized.

\subsection{Role of carbon dioxide in regulation of the bronchial tone and in local ventilation distribution}

$\mathrm{CO}_{2}$ plays an important role in the regulation of the small airway smooth muscle tone. The most important feature of this regulation is the direct effect of the low alveolar $\mathrm{CO}_{2}$ concentration on the smooth muscle cells of the lower airways. $\mathrm{CO}_{2}$ can readily penetrate the cell membrane, and the local hypocapnia around the smooth muscle cells is associated with a prompt intracellular lowering of the $\mathrm{H}^{+}$concentration. Intracellular alkalosis leads to an elevated muscle tone and a consequently increased airway resistance ${ }^{12,13}$.

Earlier investigations furnished evidence of a decreased ventilation to large lung regions made hypocapnic by unilateral main or lobar pulmonary artery occlusion, which could be prevented by adding $\mathrm{CO}_{2}$ to the inspired air ${ }^{14-16}$. Experiments performed with a multiple breath washout technique with helium and nitrogen in animal models suggest that a decrease in the level of alveolar $\mathrm{CO}_{2}$ increases the heterogeneity of the ventilation distribution between regions on the scale of acini and larger airway regions ${ }^{17}$, and even the global matching of alveolar ventilation to perfusion can decrease ${ }^{18,19}$.

This direct, rapid and local regulation of the airway tone drives the air towards lung regions or alveoli with lower input impedance because of retained perfusion. Thereby, the 
local $\mathrm{CO}_{2}$ concentration contributes to maintenance of the normal ventilation perfusion ratio of the lung parenchyma because the local ventilation depends strongly on the local $\mathrm{CO}_{2}$ concentration, as a natural consequence of local perfusion. Modification of the airway calibre under physiological and pathophysiological circumstances plays an important role in preventing wasted ventilation and normalizing the ventilation perfusion relationship subsequent to temporary changes in upright or supine body position or mucus deposition $^{12,13,20}$.

The direct relaxation potential of $\mathrm{CO}_{2}$ on the bronchial smooth muscle has been demonstrated against the bronchoconstriction induced by constrictor drugs ${ }^{19}$. Further, bronchoconstriction resulting from temporary regional pulmonary arterial occlusions is reversed by normalizing the partial tension of alveolar $\mathrm{CO}_{2}{ }^{14,21-23}$.

There is another, indirect mechanism via which the $\mathrm{CO}_{2}$ concentration can modify the airway muscle tone. The systemic $\mathrm{CO}_{2}$ level lowers the vagal withdrawal ${ }^{24}$, and the consequent enhanced vagal tone may induce airway resistance through an indirect vagal nerve-mediated regulatory pathway ${ }^{25,26}$. In addition to these indirect effects, bilateral vagotomy or cooling of the vagus nerve precludes the development of bronchoconstriction subsequent to systemic hypercapnia, demonstrating that $\mathrm{CO}_{2}$ also alters the airway calibre via indirect mechanisms mediated through the vagal reflexes ${ }^{25,26}$.

The two constrictor mechanisms mentioned above can theoretically augment each other in certain diseases, e.g. pulmonary embolism.

Clarification of the subsequent changes in the intra-alveolar $\mathrm{CO}_{2}$ concentration and the systemic blood $\mathrm{CO}_{2}$ level may facilitate an understanding of the physiological and pathophysiological alterations in various clinical conditions. The effects of intra-alveolar $\mathrm{CO}_{2}$ on airway calibre have frequently been investigated in isolated lung models by altering the fraction of inspired $\mathrm{CO}_{2}\left(\mathrm{Fi}_{\mathrm{CO}_{2}}\right)^{27-29}$. However, in the absence of physiological neural-humoral control of the airways, these earlier results did not allow a complete description of the mechanisms involved in a lung with intact nerves. In more comprehensive in vivo investigations, the alveolar $\mathrm{CO}_{2}$ concentrations have been altered by changing the breathing pattern $^{29-31}$. However, respiratory resistance and elastance change with varying lung volume and/or ventilation frequency ${ }^{32}$. Thus, an altered ventilatory pattern itself may affect the lung mechanics so that the active effects of $\mathrm{CO}_{2}$ in the lungs are biased. Alternatively, regional 
hypocapnia studied via unilateral occlusion of a pulmonary artery has been shown to elevate the airway tone ${ }^{14,21-23,28}$. Nevertheless, a compromised pulmonary perfusion also increases the systemic $\mathrm{CO}_{2}$ level, which may lead to vagally-mediated bronchoconstriction ${ }^{31}$. This phenomenon may have a synergistic constrictor effect on the affected airways, which becomes indistinguishable from the direct effects of altered intra-alveolar $\mathrm{CO}_{2}$ in the lungs. Moreover, the pulmonary arterial occlusion approach does not allow the investigation of hypercapnia and it cannot eliminate the vagal reflexes. Accordingly, none of these in vivo approaches permit a detailed characterization of how the different $\mathrm{CO}_{2}$ concentrations affect the lung mechanics, i.e. the establishment of a dose-response curve. Despite the fact that the presence of a cardiopulmonary bypass (CPB) offers ideal conditions for altering both the alveolar and circulatory $\mathrm{CO}_{2}$ levels precisely in vivo, without involvement of the biasing effects of an altered ventilation pattern or pulmonary ischaemia, the advantages of this approach have not been utilized for a systematic exploration of the effects of an altered $\mathrm{CO}_{2}$ level on the airway tone.

\subsection{Effects of volatile anaesthetic agents on lung mechanics}

Bronchoconstriction under anaesthesia can occur because of direct stimulation of the laryngeal and tracheal areas, subsequent to the administration of adjuvant drugs with a potential to induce histamine release, and from noxious stimuli activating the vagal afferent nerves. The reflex response to these stimuli may be enhanced in patients with lung diseases involving airway hyperresponsiveness, such as asthma, upper respiratory tract infection and chronic obstructive pulmonary diseases.

Early investigations reported the beneficial bronchodilator properties of halothane in preventing and treating bronchospastic episodes in humans ${ }^{33,34}$, animals ${ }^{35}$ or isolated tracheal smooth muscle ${ }^{36}$. Besides the well-known halothane, enflurane and isoflurane, the introduction of sevoflurane and desflurane during recent decades has offered new perspectives to anaesthesiologists. Routine procedures performed during the induction and maintenance of general anaesthesia achieved with volatile agents may also alter both the airway and the pulmonary parenchymal properties ${ }^{37-40}$.

Apart from the previous studies in which the bronchoactive properties of volatile agents were examined under physiological conditions, numerous earlier investigations 
assessed their abilities to alter the elevated airway tone in the presence of a lung disease ${ }^{41}$ or through the administration of constrictor agonists. A recent study of children with susceptible airways demonstrated beneficial properties of sevoflurane, whereas desflurane exhibited irritative properties even at 1 minimum alveolar concentration $(\mathrm{MAC})^{41}$. In a previous experimental study, the protective effects of all commonly applied volatile anaesthetic agents were observed against the bronchoconstriction induced by an intravenous (iv) infusion of methacholine $(\mathrm{MCh})$ under in vivo conditions ${ }^{37}$, in which the autonomic nervous system was intact. The results of that study revealed that isoflurane, sevoflurane and desflurane were as effective as halothane in protecting against MCh-induced airway constriction in healthy lungs. In allergically sensitized animals, however, isoflurane improved the lung function more efficiently than did sevoflurane or halothane during sustained MCh-induced bronchoconstriction, whereas desflurane enhanced the airway smooth muscle tone even further ${ }^{42}$.

The complex mechanisms of the effects of volatile anaesthetic agents on the lung mechanics involve multiple modes of action, which may contribute to these variable results. Isoflurane and sevoflurane have been shown to exert their effects through opening ischaemic $\mathrm{K}^{+}\left(\mathrm{K}_{\mathrm{ATP}}\right)$ channels. The activation of $\mathrm{K}_{\mathrm{ATP}}$ channels can hyperpolarize the smooth muscle cell membrane, leading to inhibition of the $\mathrm{Ca}^{2+}$ influx into the cell, and to subsequent relaxation of the airway smooth muscle ${ }^{43-45}$. Moreover, volatile anaesthetics appeared to inhibit the store-operated $\mathrm{Ca}^{2+}$ influx into airway smooth muscle cells in an animal model ${ }^{46}$. Conversely, desflurane stimulates the parasympathetic nervous system, resulting in the constriction of bronchial smooth muscle, mainly via a reflex mechanism ${ }^{43}$. Finally, the mechanical properties of the lungs may also be affected by the altered pulmonary haemodynamics observed following the administration of inhalation agents ${ }^{47}$. Although all of these previous reports had the aim of characterizing the bronchoactive properties of the volatile agents, the contributions of the direct and indirect pathways to these results have not yet been fully clarified.

While the beneficial properties of volatile anaesthetics are well established, they may also irritate the airways and initiate breath-holding, coughing and/or laryngospasm. Volatile anaesthetics differ in the concentration at which they irritate the airways, particularly during the induction of anaesthesia. Halothane and sevoflurane have minimal or no pungency at all 
concentrations applied clinically, whereas isoflurane can irritate the airways at a concentration of 1.5 MAC (approximately 1.8\%) or above ${ }^{48}$. In allergically sensitized animals, however, isoflurane improves the lung function better than do sevoflurane and halothane during sustained MCh-induced bronchoconstriction, while desflurane further enhances the airway smooth muscle tone ${ }^{42}$. Similar results have been reported in humans: at 1 MAC, isoflurane, sevoflurane and desflurane led to decreases in peak inspiratory pressure and respiratory resistance and to increases in dynamic compliance. At 2 MAC, these effects were preserved with isoflurane and sevoflurane, whereas desflurane developed bronchoconstrictive potential $^{49}$.

\subsection{Characterization of respiratory mechanics}

In clinical practice, pulmonary function tests are mainly of importance as concerns diagnoses, the monitoring of disease progression, and assessment of the effectiveness of therapies for asthma, chronic obstructive pulmonary disease ${ }^{50}$ and interstitial lung disease. The identification of the respiratory mechanical parameters specific to the airway and lung tissue compartments played a key role in the exploration of the regulatory mechanisms exerted by the neurohumoral system and by the different resident gases in the lungs.

The most comprehensive description of the mechanical properties of the respiratory system can be supplied by the forced oscillation technique (FOT), first developed in the 1950s by DuBois et al. ${ }^{51}$, which involves the generation of sinusoidal oscillations around the body surface and measurement of the impedance of the respiratory system through the application of small pressure oscillations at the mouth during normal breathing. In this pioneering work, the experiment was repeated at a number of different oscillation frequencies and the fundamental observation was established that respiratory impedance varies with frequency in a characteristic manner. Since those measurements, numerous variants in instrumentation, signal processing, and modelling relevant to FOT measurements have been developed for the assessment of various mechanical phenomena in healthy lungs and in respiratory diseases (asthma, chronic obstructive pulmonary disease and acute lung injury). Early investigations of the mechanical behaviour of the respiratory system with the FOT were also made by applying sequentially varying frequencies in mechanically ventilated humans ${ }^{52}$, and around the range of normal breathing frequencies ${ }^{53,54}$. 
The principal concept of forced oscillatory respiratory mechanics is based on the measurement of "impedance" (Z), the spectral (frequency domain) relationship between the pressure $(\mathrm{P})$ and airflow (V') which corresponds to the total pressure drop required to oscillate, i.e. to develop a flow in the respiratory system $\left(\mathrm{Z}_{\mathrm{rs}}=\mathrm{P} / \mathrm{V}^{\prime}\right)$. Generally, depending on the mechanical characteristics of the measured system, the $\mathrm{P}$ and $\mathrm{V}^{\prime}$ signals are not in phase; with a phase shift between the two signals is $\varphi$. $\mathrm{Z}_{\mathrm{rs}}$, the respiratory input impedance, can be characterized by describing its "real" (respiratory resistance, $\mathrm{R}_{\mathrm{rs}}$ ) and "imaginary" (respiratory reactance, $\mathrm{X}_{\mathrm{rs}}$ ) components:

$$
\begin{aligned}
& R_{r s}=Z_{r s} \cos \varphi \\
& X_{r s}=Z_{r s} \sin \varphi
\end{aligned}
$$

$\mathrm{R}_{\mathrm{rs}}$ describes the dissipative mechanical properties of the respiratory system (lung and thoracic tissues). $\mathrm{X}_{\mathrm{rs}}$ is related to the energy storage capacity at low oscillation frequencies and is therefore determined by the elastic properties of the respiratory tissues (the relationship between $\mathrm{P}$ and volume), whereas the inertive properties progressively become more important with increasing oscillation frequency (the relationship between $\mathrm{P}$ and volume acceleration) ${ }^{55}$.

The impedance data obtained at the airway opening reflect mainly the overall central conducting airway geometry. However, the mechanical properties of the lung periphery are the major determinants of the overall lung function, and can change dramatically in disease. The investigations of the peripheral airways (called the "silent zone" of the lung), which are relatively inaccessible at the level of the whole organ, were based on application of the alveolar capsule technique, which allowed direct measurements of alveolar pressure in openchest preparations ${ }^{56}$. To determinate the mechanical properties of the individual components of the pulmonary system and to partition the pulmonary impedance into airway and tissue components, the alveolar capsule technique was combined with the FOT $^{57}$ in experimental animals, including dogs ${ }^{57,58}$, rabbits ${ }^{59}$, rats $^{60}$ and mice ${ }^{61}$. Simultaneous measurements from multiple capsules have shown that the alveolar pressure becomes increasingly heterogeneous as bronchoconstriction develops ${ }^{58}$, which may provide important physiological information. This heterogeneity apparently demonstrates the inherent limitation of this technique due to the inevitable undersampling of alveolar pressures in consequence of the finite size of the capsule and the fact that it can only access subpleural alveoli ${ }^{61}$. 
Since the airway and tissue compartments exhibit distinctly different frequencydomain behaviour, a model-based evaluation of the pulmonary and respiratory impedance data offers a valuable alternative to the capsule-based separation of the airway and tissue mechanics. To achieve this comprehensive description, the lung viscoelasticity was extensively evaluated in the early 1970s by Hildebrandt and co-workers. In their studies, the linear viscoelastic phenomena of the pulmonary system were resolved. Furthermore, the derived linear model in the time domain exhibited characteristics such as stress relaxation and dynamic hysteresis ascribed to viscoelasticity ${ }^{62,63}$. If these properties are examined in the frequency domain, the airways and respiratory system tissues reveal characteristically different dependences on frequency that allow separation of their contributions to impedance on the basis of mathematical models ${ }^{58,64}$. An important aspect of the coupling of resistive and elastic properties in the respiratory tissues was highlighted by Fredberg and Stamenovic, who demonstrated that the relationship between the frictional and elastic stresses in the lung tissue is nearly invariant; the frictional stress is invariable between $10 \%$ and $20 \%$ of the elastic stress. The ratio of the viscous and elastic stresses is referred to as the structural damping coefficient, or "hysteresivity" 65 .

In routine clinical applications of FOT, it is recommended to use oscillation frequencies higher than $2-4 \mathrm{~Hz}$ if the oscillatory signal is superimposed on the spontaneous breathing $^{55}$. In this medium-frequency range, the imposed oscillations start roughly 1 decade above the spontaneous breathing rate and extend up to a few times $10 \mathrm{~Hz}$. The measured impedance spectra in the healthy respiratory system exhibit a largely frequency-independent $\mathrm{R}_{\mathrm{rs}}$, whose major component is the airway resistance $\left(\mathrm{R}_{\mathrm{aw}}\right)$.

\subsubsection{Low-frequency forced oscillation technique}

Over the low-frequency range (below $2 \mathrm{~Hz}$ ), the respiratory tissues predominate and the steep increase in reactance with frequency is mirrored by a marked decrease in resistance. In the medium-frequency range $(2-40 \mathrm{~Hz})$, the resistance expresses no more than mild changes, while at the first resonance (reactance $=0$ ) the reactance undergoes a transition from dominance by the tissue elastic properties to dominance by the inertial properties of the gas in the airways ${ }^{66}$. 
The characteristic rheology of the structures of the respiratory tissues below $2 \mathrm{~Hz}$ can be established by investigation during voluntary apnoea, as has been demonstrated between 0.25 and $5 \mathrm{~Hz}$ in healthy humans by using the oesophageal balloon technique ${ }^{54}$ or between 0.25 and $32 \mathrm{~Hz}$ in anaesthetized and paralysed patients ${ }^{67}$. Through utilization of these characteristic frequency dependences, a separate assessment of the airway and pulmonary parenchymal mechanics is possible by the application of forced oscillations at low frequencies $^{58}$. A loudspeaker-in-box measurement system generating the pseudorandom broadband, low-frequency oscillatory pressure signals was specially designed to provide the excitatory pressure signal necessary for measurement of the input impedance spectra of the pulmonary system $\left(\mathrm{Z}_{\mathrm{L}}\right)$ during short intervals of suspended mechanical ventilation at endexpiration.

Several investigations have indicated that the airways can be described by a frequency-independent $\mathrm{R}_{\mathrm{aw}}$ and inertance $\left(\mathrm{I}_{\mathrm{aw}}\right)^{58}$. Conversely, both the parenchymal resistance and reactance have been reported to decrease roughly in inverse proportion to increasing frequency. Thus, to separate the airway and lung parenchymal mechanical properties, a model containing a frequency-independent $\mathrm{R}_{\mathrm{aw}}$ and $\mathrm{I}_{\mathrm{aw}}$ in series with a constant-phase tissue model $^{58,68}$, including parenchymal damping $(\mathrm{G})$ and elastance $(\mathrm{H})$, can be fitted to the $\mathrm{Z}_{\mathrm{L}}$ spectra by minimizing the relative differences between the measured and modelled impedance values:

$$
\mathrm{Z}_{\mathrm{L}}=\mathrm{R}_{\mathrm{aw}}+\mathrm{j} \omega \mathrm{I}_{\mathrm{aw}}+(\mathrm{G}-\mathrm{jH}) / \omega^{\alpha}
$$

where $j$ is the imaginary unit, $\omega$ is the angular frequency $(2 \pi f)$, and $\alpha=2 / \pi \arctan (H / G)$.

The parameters $R_{a w}$ and $I_{a w}$ can be attributed to the airways, while $G$ and $H$ represent the viscous (damping or resistive component) and elastic properties, respectively, of the lung parenchyma. The lung tissue hysteresivity $(\eta)$ is calculated as $\eta=G / H^{65}$. The optimization procedure is used with a relative (weighted) fitting criterion in most cases to give equal weight to the low and high-frequency components: the differences between the measured and modelled impedance values are normalized by the impedance magnitude at each frequency point $^{69}$. 


\section{Aims of the studies included in the present thesis}

The primary purpose of the present thesis is to characterize the effects of an altered resident gas on the pulmonary mechanics, with particular focus on achieving a better understanding of the potencies of $\mathrm{CO}_{2}$ and volatile anaesthetic agents on the pulmonary system by separating the airway and tissue mechanical responses occurring in routine clinical anaesthetic practice. Various studies included in the present thesis were therefore designed:

a) To establish a dose-response curve relating to a wide range of alveolar $\mathrm{CO}_{2}$ levels without affecting the ventilation pattern. To achieve this aim, measurements were made in open-chest animal models subjected to a CPB.

b) To characterize the airway and pulmonary tissue consequences of systemic hypercapnia and acidosis.

c) To clarify the role of vagal activity in the regulation of the airway tone related to altered systemic $\mathrm{CO}_{2}$ concentrations.

d) To characterize and, more specifically, to compare the bronchoactive properties of the volatile agents used routinely in clinical practice in the absence of an airway tone.

e) To clarify the relaxation properties of the volatile agents against the airway constriction induced by administration of a bronchoactive drug in the absence of neural control of the tracheobronchial tree.

\section{Materials and methods}

\subsection{Animal models and materials}

All of the animal models were chosen with regard to their suitability for the experiments in question and for measurement of the pulmonary mechanics. Accordingly, the investigation of the effects of $\mathrm{CO}_{2}$ required the application of a CPB; a dog model was chosen for these experiments since the complicated surgical procedure can be carried out successfully in this species. Isolated perfused rat lungs were selected for investigations of the protective effects of volatile agents against lung constriction in the absence of a neural control, since the rat is the animal most commonly applied in studies of the respiratory consequences of MCh and volatile agents ${ }^{37}$, and our research group has acquired extensive experience in performing such experiments. The animal experimental protocols were approved by the Institutional 
Animal Care Committee of the Canton of Geneva in Switzerland (rat experiments) and the Institutional Animal Care and Use Committee of the University of Szeged in Hungary (dog experiments).

\subsubsection{Open-chest dogs with a cardiopulmonary bypass}

Eight adult mongrel dogs [mean body weight \pm standard error $(\mathrm{SE}), 23.7 \pm 5.0 \mathrm{~kg}$ ] were anaesthetized (30 mg/kg pentobarbital, iv). Analgesia was provided by iv injections of fentanyl $(5-10 \mu \mathrm{g} / \mathrm{kg})$. Muscle relaxation was achieved with an iv bolus of pipecuronium bromide $(0.1 \mathrm{mg} / \mathrm{kg})$. The dogs were then intubated with an 8-9-mm-internal diameter (ID) cuffed endotracheal tube (Portex, Hythe, UK) and ventilated with a Siemens Servo 900C Ventilator (Solna, Sweden) in volume-controlled mode. A tidal volume of $10 \mathrm{ml} / \mathrm{kg}$ and a positive end-expiratory pressure (PEEP) of $5 \mathrm{cmH}_{2} \mathrm{O}$ were applied, and the frequency was set to maintain a normal arterial $\mathrm{CO}_{2}$ level $(40 \mathrm{mmHg})$ in the pre-bypass period. The anaesthesia was maintained by continuous iv infusion of propofol $(50 \mu \mathrm{g} / \mathrm{kg} / \mathrm{min})$ and the muscle relaxant was administered as needed. After opening of the chest by a midline sternotomy, anticoagulant (heparin, $3 \mathrm{mg} / \mathrm{kg}$, iv) was administered. The ascending aorta and the inferior and superior vena cava were then cannulated, and the CPB was achieved by means of a roller pump (Pemco, Inc., Cleveland, OH, USA) with non-pulsatile blood flow at $100 \mathrm{ml} / \mathrm{kg} / \mathrm{min}$ and use of a membrane oxygenator (Spiral Gold Buxter Healthcare Irvine, CA, USA). A left vent was introduced into the left ventricle through the right upper pulmonary vein. During total $\mathrm{CPB}$, the pulmonary circulation was ceased and the lungs were ventilated with a gas mixture of $50 \% \mathrm{O}_{2}$ in air with a controlled concentration of $\mathrm{CO}_{2}$ added to this gas mixture from a cylinder attached to the low-pressure gas input of the respirator. The end-tidal partial pressure of $\mathrm{CO}_{2}\left(\mathrm{PET}_{\mathrm{CO}_{2}}\right)$ and $\mathrm{Fi}_{\mathrm{CO}_{2}}$ were monitored (Datex, Oscar Helsinki, Finland). Arterial blood gas samples were analysed (model 505, Acid Base Laboratory, Copenhagen, Denmark).

\subsubsection{Isolated perfused rat lung model}

Thirty-five adult male Sprague-Dawley rats $(373 \pm 4.17 \mathrm{~g})$ were anaesthetized with 50 $\mathrm{mg} / \mathrm{kg}$ pentobarbital (Nembutal) intraperitoneally (ip). The rats were then tracheotomized with a polyethylene cannula (14-gauge, Braun, Melsungen, Germany) using sterile techniques, and normoventilated mechanically with a tidal volume of $7 \mathrm{ml} / \mathrm{kg}$ body weight. A 
PEEP of $2.5 \mathrm{cmH}_{2} \mathrm{O}$ was applied, together with a respiratory rate of $70-80$ breaths/min with a constant volume-cycled rodent ventilator (model 683, Harvard Apparatus Co. Inc., South Natick, MA, USA). After induction, anaesthesia was maintained with iv injections of pentobarbital when required $(10 \mathrm{mg} / \mathrm{kg})$. Analgesia was provided by the continuous infusion of fentanyl at $2 \mu \mathrm{g} / \mathrm{kg} / \mathrm{h}$. In one group of rats, the induction and maintenance of anaesthesia were achieved with Nembutal (50 mg/kg ip for induction and $10 \mathrm{mg} / \mathrm{kg}$ iv for maintenance); these animals served as a control group without the application of volatile anaesthetics. Respiratory gases were monitored continuously with a Datex monitor (Ultima ${ }^{\mathrm{TM}}$, Datex/Instrumentarium, Helsinki, Finland), and the airway pressure $\left(\mathrm{P}_{\mathrm{aw}}\right)$ was also measured continuously with a calibrated pressure transducer (Validyne DP 45 and Validyne model 2D15 carrier demodulator, Northridge, CA, USA). The femoral vessels were cannulated (28gauge catheter, Portex, Hythe, Kent, UK) for blood sampling and continuous arterial blood pressure monitoring, using a calibrated pressure transducer (Honeywell, model 156-PC 06GW2, Zurich, Switzerland). The rats were fully anticoagulated with $1.5 \mathrm{IU} / \mathrm{g}$ body weight heparin injected iv. Twenty-five millilitres of blood was then gently withdrawn over 5 min via the arterial cannula, the collected blood being replaced continuously by the iv infusion of a $6 \%$ colloid solution of hydroxyethyl-starch at a constant rate in order to maintain a constant intravascular and systemic blood pressure above $50 \mathrm{mmHg}$, so as to minimize lung ischaemic lesions during this normovolaemic haemodilution procedure. The collected diluted blood was centrifuged (1800 $\mathrm{g}$ for $10 \mathrm{~min}$ ), and $7 \mathrm{ml}$ of plasma was extracted. The resulting concentrated blood, with a haematocrit of around 30\%, served as the priming volume for the isolated perfusion circuit. A midline sternotomy was next performed; the chest was widely retracted, and a heart-lung block was prepared, as described in detail previously ${ }^{70}$.

Procedure and continuous monitoring of the isolated lung model: The heart-lung block was placed in a thermostatically controlled and humidified Plexiglas chamber (Figure $1)^{70}$, as detailed previously ${ }^{70}$.

The lungs were ventilated with room air mixed with $5 \% \mathrm{CO}_{2}$, and a respiratory rate of $50 / \mathrm{min}$, a tidal volume of $7 \mathrm{ml} / \mathrm{kg}$, and a PEEP of $2.5 \mathrm{cmH}_{2} \mathrm{O}$ were maintained. A series of hyperinflations (peak pressure, 25-30 $\mathrm{cmH}_{2} \mathrm{O}$ ) were applied in order to standardize the lung history by eliminating the atelectatic areas. The perfusion circuit was primed with the rat's own blood after filtration (standard 200-mm filter) to remove possible debris. Lung perfusion 
was performed from a perfusion reservoir initially at a pulmonary artery perfusion pressure $\left(\mathrm{P}_{\mathrm{pa}}\right)$ of $15 \mathrm{mmHg}$. The distal extremity of the left ventricular outflow cannula was placed at a sufficient height to obtain a left atrial pressure $\left(\mathrm{P}_{\mathrm{la}}\right)$ of $7.5 \pm 2 \mathrm{mmHg}$ at the beginning of reperfusion, which resulted in West zone 3 conditions $\left(\mathrm{P}_{\mathrm{pa}}>\mathrm{P}_{\mathrm{la}}>\right.$ mean $\left.\mathrm{P}_{\mathrm{aw}}\right)$. The blood dripping from this cannula was collected in a 5-ml collection cylinder, and aspirated from this reservoir with polyethylene tubing passing through a roller pump (Ismatec Pump, Glattburg, Zurich, Switzerland). The priming volume of the tubing and reservoirs was $18 \mathrm{ml}$. A transittime flowmeter (T-201 CDS, Transonic Systems Inc., Ithaca, NY, USA) was placed between the perfusion reservoir and the catheter cannulating the main pulmonary artery for continuous monitoring of the pulmonary blood flow $\left(\mathrm{Q}_{\mathrm{p}}\right)$. The mean $\mathrm{P}_{\mathrm{pa}}$ and $\mathrm{P}_{\mathrm{la}}$ values were measured continuously, using calibrated pressure transducers (Honeywell, model 156-PC 06-GW2) zeroed at the level of the lung hilus. The pulmonary vascular resistance $\left(\mathrm{R}_{\mathrm{v}}\right)$ was calculated by dividing the pressure drop on the pulmonary vasculature by $\mathrm{Q}_{\mathrm{p}}$.

The airflow, tidal volume, pressures and circuit flow were recorded and stored at a sampling rate of $50 \mathrm{~Hz}$ via an analogue-to-digital interface converter (Biopac, Santa Barbara, CA, USA). The perfusate temperature and $\mathrm{pH}$ were measured with a $\mathrm{pH}$-meter $(691 \mathrm{pH}-$ meter, Metrohm, Herisau, Switzerland), or the $\mathrm{pH}$ was determined on repeated blood gas samples. It was maintained between pH 7.35 and 7.45 and, if necessary, was corrected with sodium bicarbonate or a change in inspired $\mathrm{CO}_{2}$ as required by the blood gas analysis (model 505, Acid Base Laboratory, Copenhagen, Denmark). Steady-state gas exchange was confirmed by stable $\mathrm{Pa}_{2}, \mathrm{~Pa}_{\mathrm{CO}_{2}}$ and haematocrit levels during the experiments.

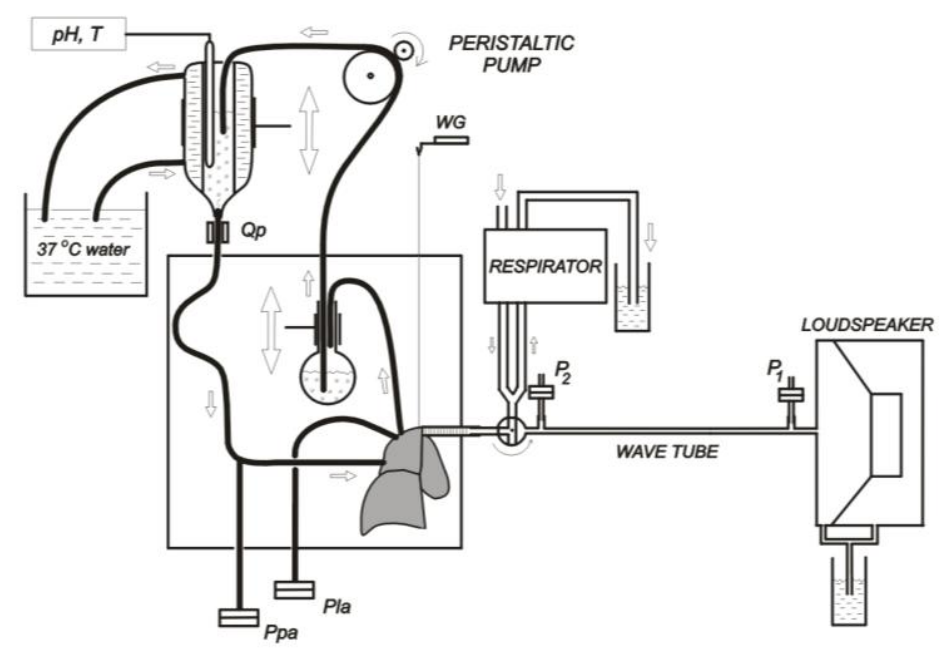

Figure 1. Schematic illustration of the isolated perfused lung experimental setup. pH: blood pH; T: blood temperature; WG: weight gain; $P_{l a}$ : left atrial pressure; $P_{p a}$ : pulmonary arterial pressure; $Q_{p}$ : pulmonary blood flow; $P_{1}$ and $P_{2}$ :lateral pressures. 


\subsection{Measurement of lung mechanics}

\subsubsection{Impedance measurements with the classical set-up in open-chest dogs during a cardiopulmonary bypass}

The measurement system for the collection of the forced oscillatory input impedance spectra of $\mathrm{Z}_{\mathrm{L}}$ was similar to that described in detail previously ${ }^{58}$. The set-up used for impedance measurements during short intervals of suspended mechanical ventilation is shown schematically in Figure 2.

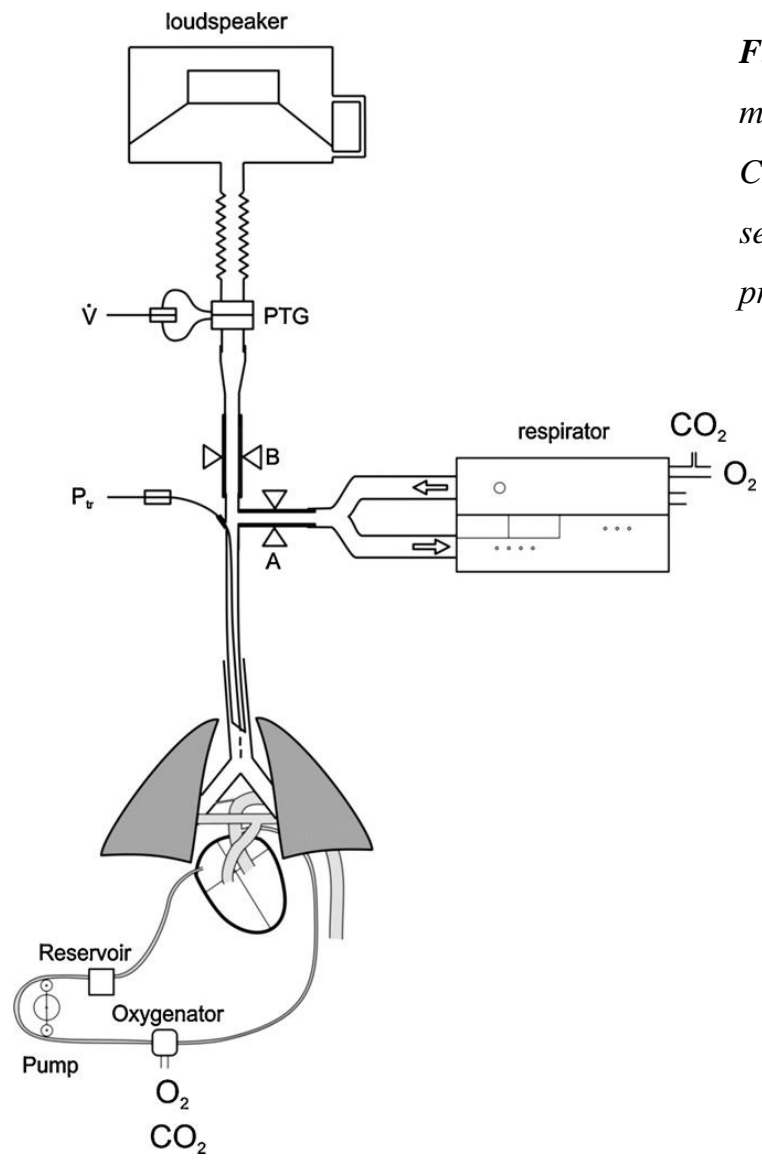

Figure 2. Schematic illustration of the measurement set-up for open-chest dogs during a CPB. $A$ and $B$ denote collapsible latex tube segments. PTG: pneumotachograph; $P_{t r}$ : tracheal pressure; V': tracheal flow.

Two collapsible latex tube segments (A and B) were clamped alternately to switch the endotracheal tube from the respirator to the oscillatory device and back, as follows. During mechanical ventilation, segment A was open and segment B was closed. Following a few ventilatory cycles, the respirator was stopped at end-expiration and its tubing was detached from segment A. Segment B was then opened and segment A was clamped. In this apnoeic period, small-amplitude (1.5 $\mathrm{cmH}_{2} \mathrm{O}$ peak-to-peak) pseudorandom pressure excitations were delivered by the loudspeaker into the trachea. The forcing signal contained 30 integermultiple frequency components between $0.2 \mathrm{~Hz}$ and $6 \mathrm{~Hz}$; the $15-\mathrm{s}$ long recordings included 3 
complete cycles of the periodic forcing signal. Tracheal flow (V') was measured with a 28$\mathrm{mm}$ ID screen pneumotachograph connected to a differential pressure transducer (ICS Model 33NA002D; ICSensors, Miltipas, CA, USA). To exclude endotracheal tube impedance from the measurements, tracheal pressure $\left(\mathrm{P}_{\mathrm{tr}}\right)$ was measured with an identical pressure transducer through a 1.5 -mm-outer diameter polyethylene catheter, the tip of which, containing several lateral holes, was positioned $1.5-2 \mathrm{~cm}$ over the distal end of the endotracheal tube. The crosspower spectra between the electric signal driving the loudspeaker and the measured signals of $\mathrm{P}_{\text {tr }}$ and $\mathrm{V}$ ' were computed by fast Fourier transformation with 10 -s time windows and $95 \%$ overlapping $\left(\mathrm{Z}_{\mathrm{L}}=\mathrm{P}_{\mathrm{tr}} / \mathrm{V}^{\prime}\right)$.

\subsubsection{Wave-tube technique in isolated perfused rat lungs}

The respective contributions of the airway and lung parenchymal mechanical properties to the total lung resistance were estimated by measuring the forced oscillatory $\mathrm{Z}_{\mathrm{L}}$ ex vivo (isolated perfused rat lung) with the wave-tube technique, as described in detail previously ${ }^{70}$ and demonstrated schematically in Figure $1^{70}$. Briefly, in this set-up, a three-way tap was used to switch the tracheal cannula from the respirator to a loudspeaker-in-box system at end-expiration. Before each measurement, the pressure in the box chambers was adjusted to $2.5 \mathrm{cmH}_{2} \mathrm{O}$ to keep the transpulmonary pressure constant during the measurements. The loudspeaker delivered a computer-generated, small-amplitude pseudorandom signal with frequency components between 0.5 and $20.75 \mathrm{~Hz}$ through a polyethylene wave-tube with known geometry (polyethylene tube: length (L), $100 \mathrm{~cm}$; ID: $2 \mathrm{~mm}$ ). The wave-tube was equipped with side-arms and miniature identical transducers (ICS model 33NA002D, ICSensors, Malpitas, CA, USA) to measure the lateral pressures at the loudspeaker end $\left(\mathrm{P}_{1}\right)$ and the cannula end $\left(\mathrm{P}_{2}\right)$.

The pressure transfer functions (i.e. $\mathrm{P}_{1} / \mathrm{P}_{2}$ ) were computed by fast Fourier transformation from the 6-s recordings, using 4-s time windows and 95\% overlapping. According to transmission line theory, $\mathrm{Z}_{\mathrm{L}}$ can be calculated from the $\mathrm{P}_{1} / \mathrm{P}_{2}$ spectra as the load impedance of the wave-tube ${ }^{71}$ :

$$
\left.\mathrm{Z}_{\mathrm{L}}=\mathrm{Z}_{0} \sinh (\gamma \mathrm{L}) /\left[\mathrm{P}_{1} / \mathrm{P}_{2}\right)-\cosh (\gamma \mathrm{L})\right]
$$

where $L$ is the length, $Z_{0}$ is the characteristic impedance and $\gamma$ is the complex propagation wave number of the wave-tube. The last two parameters were determined by the geometrical 
data and the material constants of the tube wall and the air. The load impedance of the endotracheal tube and the connecting tubing was also determined, and the $\mathrm{R}_{\mathrm{aw}}$ and $\mathrm{I}_{\mathrm{aw}}$ values were corrected by subtracting the instrumental resistance and inertance values from them.

\subsection{Study designs}

\subsubsection{Lung mechanical changes during alveolar hypocapnia and hypercapnia in dogs under a cardiopulmonary bypass}

In the in vivo open-chest dog experiments, after surgical preparation, alveolar hypocapnia was induced by applying a total bypass with cessation of the pulmonary blood flow. This manoeuvre allowed the decrease of $\mathrm{PET}_{\mathrm{CO}_{2}}$ to approximately $0.1-0.3 \%(\sim 0.8-2.3$ $\mathrm{mmHg}$ ). A set of $\mathrm{Z}_{\mathrm{L}}$ data was collected under these conditions. The alveolar $\mathrm{CO}_{2}$ concentration was then increased to $7 \%(\sim 53 \mathrm{mmHg})$ by applying stepwise elevations of $\mathrm{Fi}_{\mathrm{CO}_{2}}$, accomplished by altering the $\mathrm{CO}_{2}$ flow from the cylinder attached to the low-pressure input of the respirator. After a 2-3-min period for the animal to reach equilibrium, other sets of $\mathrm{Z}_{\mathrm{L}}$ data, including 3-5 data epochs, were collected at each $\mathrm{PET}_{\mathrm{CO}_{2}}$ level.

\subsubsection{Changes in lung mechanics by systemic hypercapnia and acidosis during a cardiopulmonary bypass in an open-chest dog model}

In a subgroup of 5 dogs, the effects of systemic $\mathrm{CO}_{2}$ changes were also investigated. After the recording of the dose-response curve to alveolar $\mathrm{CO}_{2}, \mathrm{Fi}_{\mathrm{CO}_{2}}$ was set to zero. Ten min later, $\mathrm{CO}_{2}$ was added to the oxygenator to achieve a $\mathrm{Pa}_{\mathrm{CO}_{2}}$ of $60 \mathrm{mmHg}$ and an arterial $\mathrm{pH}$ of approximately 7.2, and a set of $\mathrm{Z}_{\mathrm{L}}$ spectra were recorded after these target values had been established. To assess the role of the vagal control of the lungs under these conditions, a bolus of atropine $(0.5 \mathrm{mg})$ was injected into the iv port of the blood reservoir in order to eliminate the vagal tone, and the $\mathrm{Z}_{\mathrm{L}}$ measurements were then repeated.

\subsubsection{Effects of volatile anaesthetic agents against acetylcholine-induced}

\section{bronchoconstriction in isolated perfused rat lungs}

In the isolated perfused lung set-up, rats were randomly assigned to one or other of the following five protocol groups: group $\mathrm{C}$ (control group, $n=6$ ), no volatile anaesthetic was 
administered; group $\mathrm{H}(n=6)$, halothane group; group I $(n=9)$, isoflurane group; group $\mathrm{S}$ ( $n$ =6), sevoflurane group; and group $\mathrm{D}(n=8)$, desflurane group. As illustrated in Figure 3, after the start of perfusion of the isolated rat lung, a period of 20-30 min was allowed for the pulmonary and haemodynamic variables to reach steady-state conditions and for the preparation to become isogravimetric. Before the administration of $\mathrm{ACh}$, as constrictor agent, the lungs were hyperinflated by superimposing two inspiratory cycles to standardize the volume history. After 4-6 successive baseline $\mathrm{Z}_{\mathrm{L}}$ recordings, the concentration of $\mathrm{ACh}$ in the blood container supporting the pulmonary artery was doubled from 100 to $200 \mu \mathrm{g} / \mathrm{kg}$, and $\mathrm{Z}_{\mathrm{L}}$ was then recorded at 15 -s.

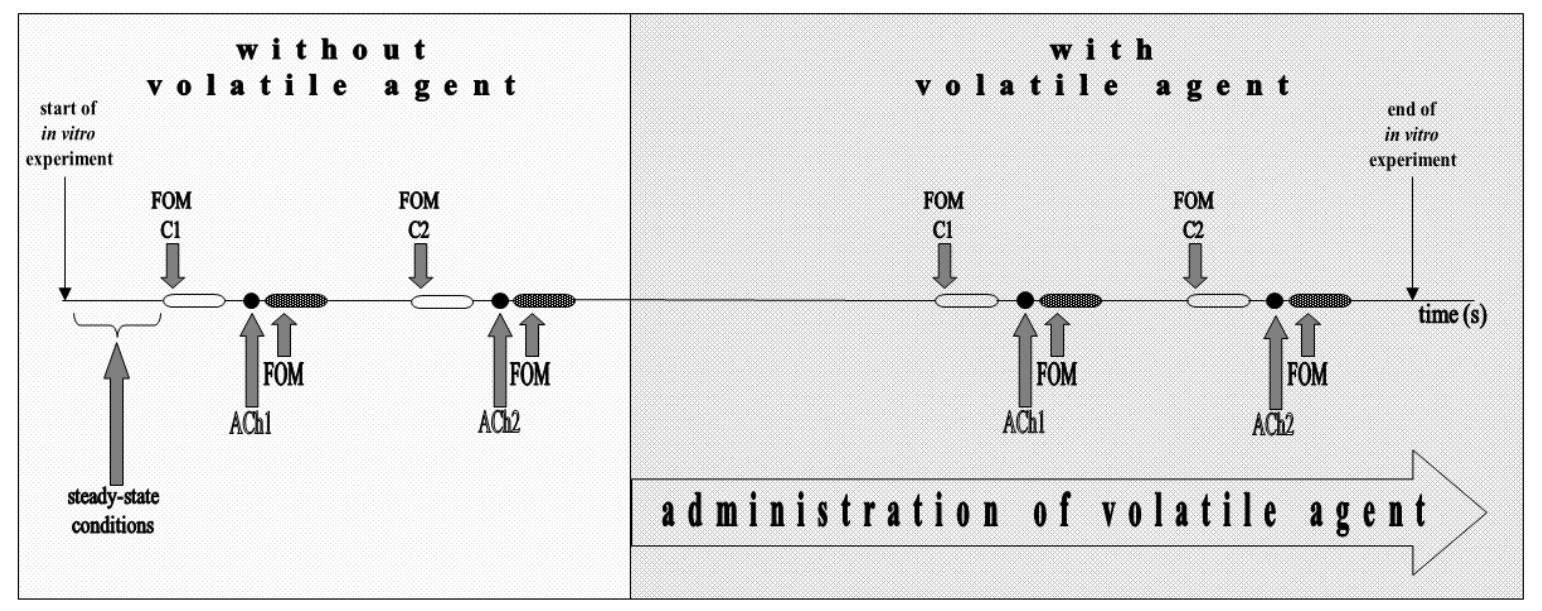

Figure 3. Schematic illustration of the experimental protocol employed in isolated perfused rat lungs. FOM: forced oscillatory measurements. C1 and C2: control conditions before the first and second ACh doses, respectively. ACh1: acetylcholine dose of $100 \mu \mathrm{g} / \mathrm{kg}$; ACh2: acetylcholine dose of $200 \mu \mathrm{g} / \mathrm{kg}$.

When the end-tidal concentration of the volatile agent reached $1 \mathrm{MAC}[1 \%$ for halothane, $1.4 \%$ for isoflurane, $2.4 \%$ for sevoflurane and $6.9 \%$ for desflurane] and stable haemodynamic conditions had been established, $\mathrm{Z}_{\mathrm{L}}$ measurements were performed to obtain new baseline data, and the ACh challenge was repeated. The concentrations of $\mathrm{O}_{2}, \mathrm{CO}_{2}$ and the volatile agent were monitored throughout the study (Ultima ${ }^{\mathrm{TM}}$, Datex/Instrumentarium).

\subsection{Statistical evaluations}

Scatters in parameters are expressed as SE values. The Kolmogorov-Smirnov test was used to test data for normality. One-way analysis of variance (ANOVA) was applied to compare the measured parameters between the independent protocol groups. Within the 
protocol groups, repeated measures one-way ANOVA was performed to compare the relative changes in the measured parameters. The Student-Newman-Keuls multiple comparison procedure based on the means was applied to compare the data obtained in the different protocol groups and/or under the different conditions. Paired $t$-tests were applied to assess statistical significance under different conditions in the same groups. Statistical tests were performed with significance level set at $p<0.05$.

\section{Results}

\subsection{Alterations in lung mechanics by alveolar hypocapnia and hypercapnia}

Representative pulmonary impedance data obtained under normocapnia and alveolar hypocapnia are demonstrated in Figure 4. The impedance data show the characteristic frequency dependence, with a sharp decrease in the real part at low frequencies mirrored by a similar increase in the imaginary part. The real part reaches a plateau at higher frequencies representing $\mathrm{R}_{\mathrm{aw}}$, while the imaginary part exhibits a fairly linear increase due to the inertive properties.

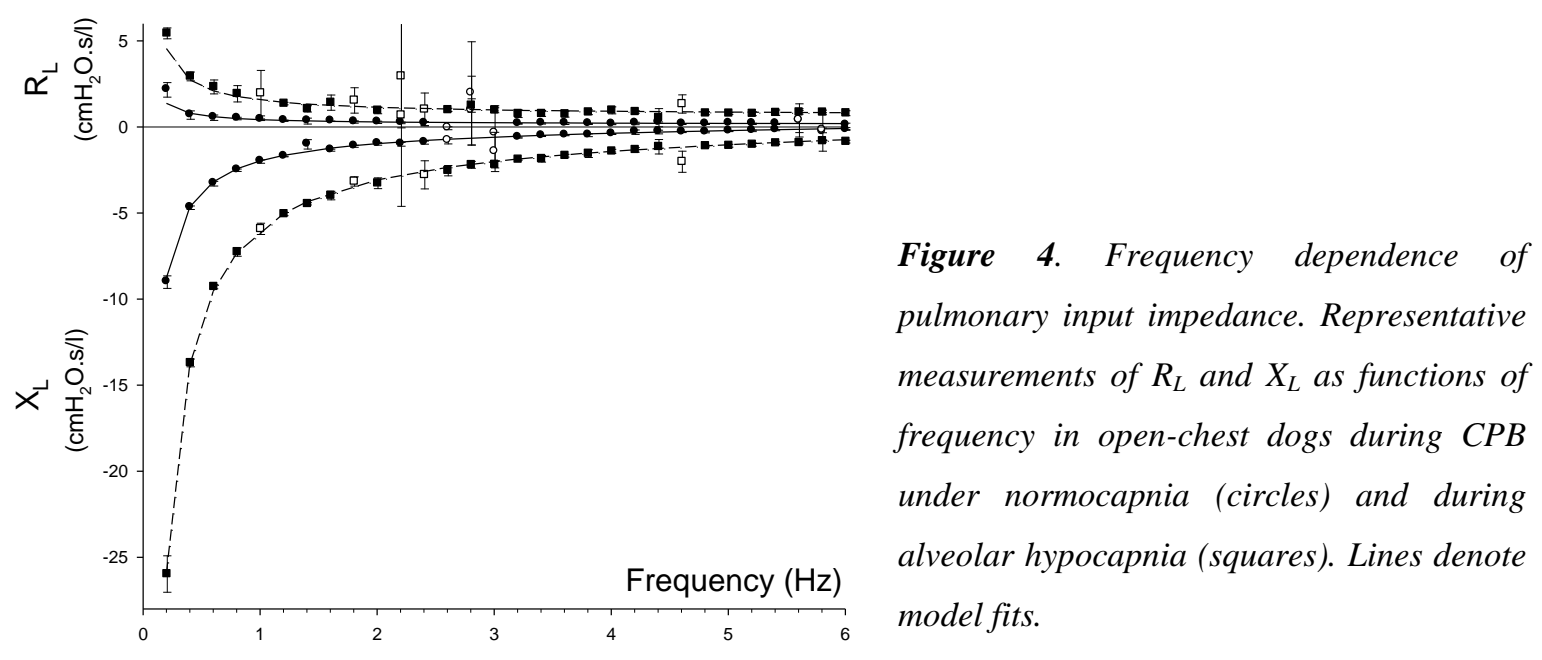

The effects of $\mathrm{Fi}_{\mathrm{CO}_{2}}$ on the airway and lung tissue mechanical parameters are demonstrated in Figure 5 for individual animals. A tendency to a decrease in $\mathrm{R}_{\mathrm{aw}}$ is obvious at low $\mathrm{Fi}_{\mathrm{CO}_{2}}$ levels (below $\sim 2 \%$ ), while $\mathrm{G}$ exhibits milder increases only in the presence of more severe hypocapnia (below $\sim 1 \%$ ). The changes in $\mathrm{I}_{\mathrm{aw}}$ and $\mathrm{H}$ were rather variable, with some 
animals exhibiting mild decreases, and others small increases with decreasing $\mathrm{Fi}_{\mathrm{CO}_{2}}$. Alveolar hypercapnia $\left(\mathrm{Fi}_{\mathrm{CO}_{2}}>6 \%\right)$ had no effect on any respiratory mechanical parameter.
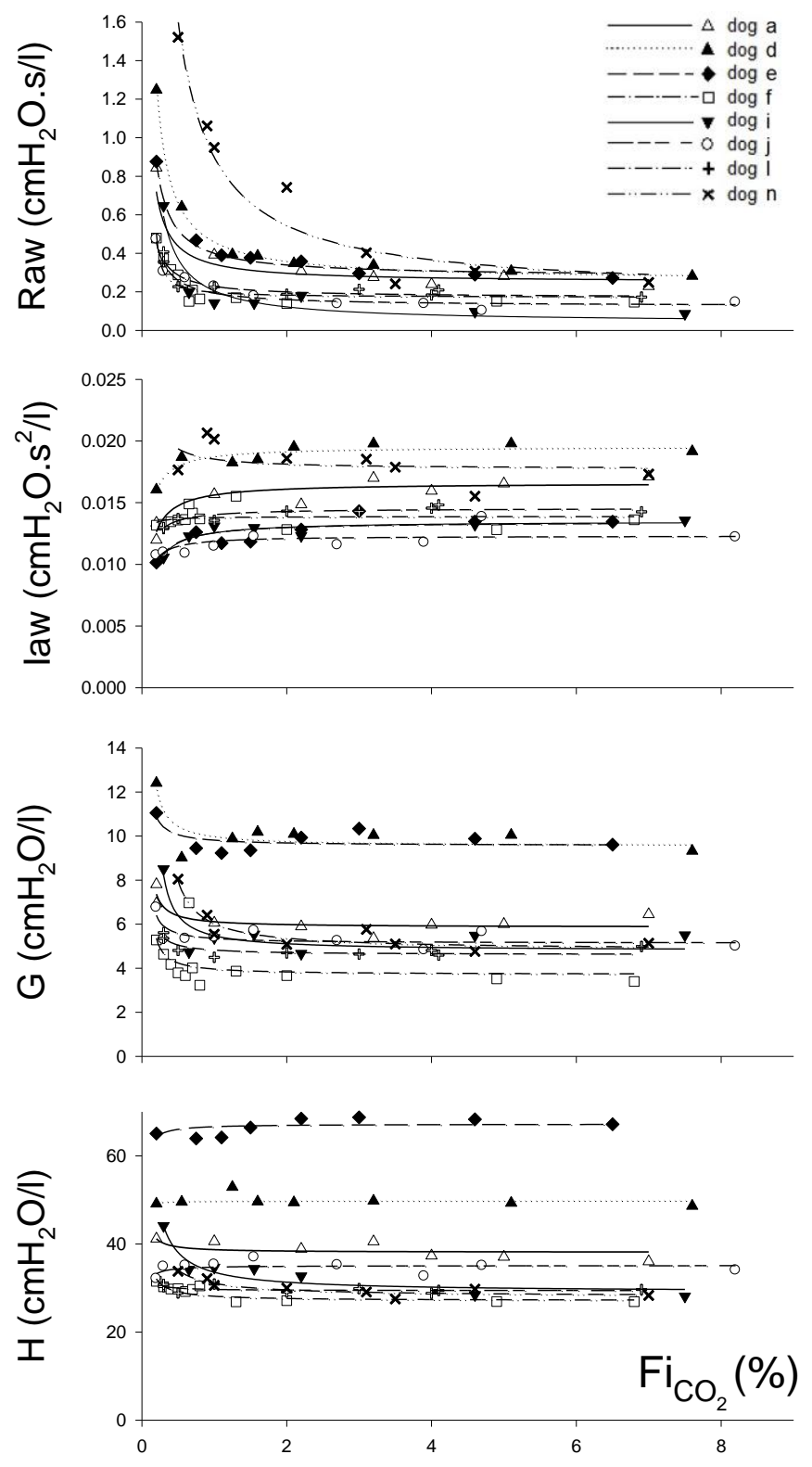

Figure 5. The effects of $\mathrm{Fi}_{\mathrm{CO}_{2}}$ on the airway and lung tissue mechanical parameters of individual animals during a CPB. Values were fitted to hyperbolas. $R_{a w}$ : airway resistance, $I_{a w}$ : airway inertance, $G$ : lung parenchymal damping, $\mathrm{H}$ : lung parenchymal elastance, $\mathrm{Fi}_{\mathrm{CO}_{2}}$ : fraction of inspired carbon dioxide.

For a precise statistical evaluation of the changes in the respiratory mechanics in response to the alterations of $\mathrm{Fi}_{\mathrm{CO}_{2}}$ in the dogs in vivo, the values of the model parameters 
were obtained at discrete $\mathrm{Fi}_{\mathrm{CO}_{2}}$ levels of $0.2 \%(1.5 \mathrm{mmHg}), 0.3 \%(2.3 \mathrm{mmHg}), 0.5 \%$ (3.8 $\mathrm{mmHg})$ and $1-7 \%(7.6-53 \mathrm{mmHg})$ by reading their interpolated values from fitted hyperbolas to $\mathrm{Fi}_{\mathrm{CO}_{2}}$ vs. $\mathrm{R}_{\mathrm{aw}}, \mathrm{I}_{\mathrm{aw}}, \mathrm{G}, \mathrm{H}$ and $\eta$ data in each individual animal. Figure 6 depicts the group means of these values for the airway and lung parenchymal mechanical parameters.
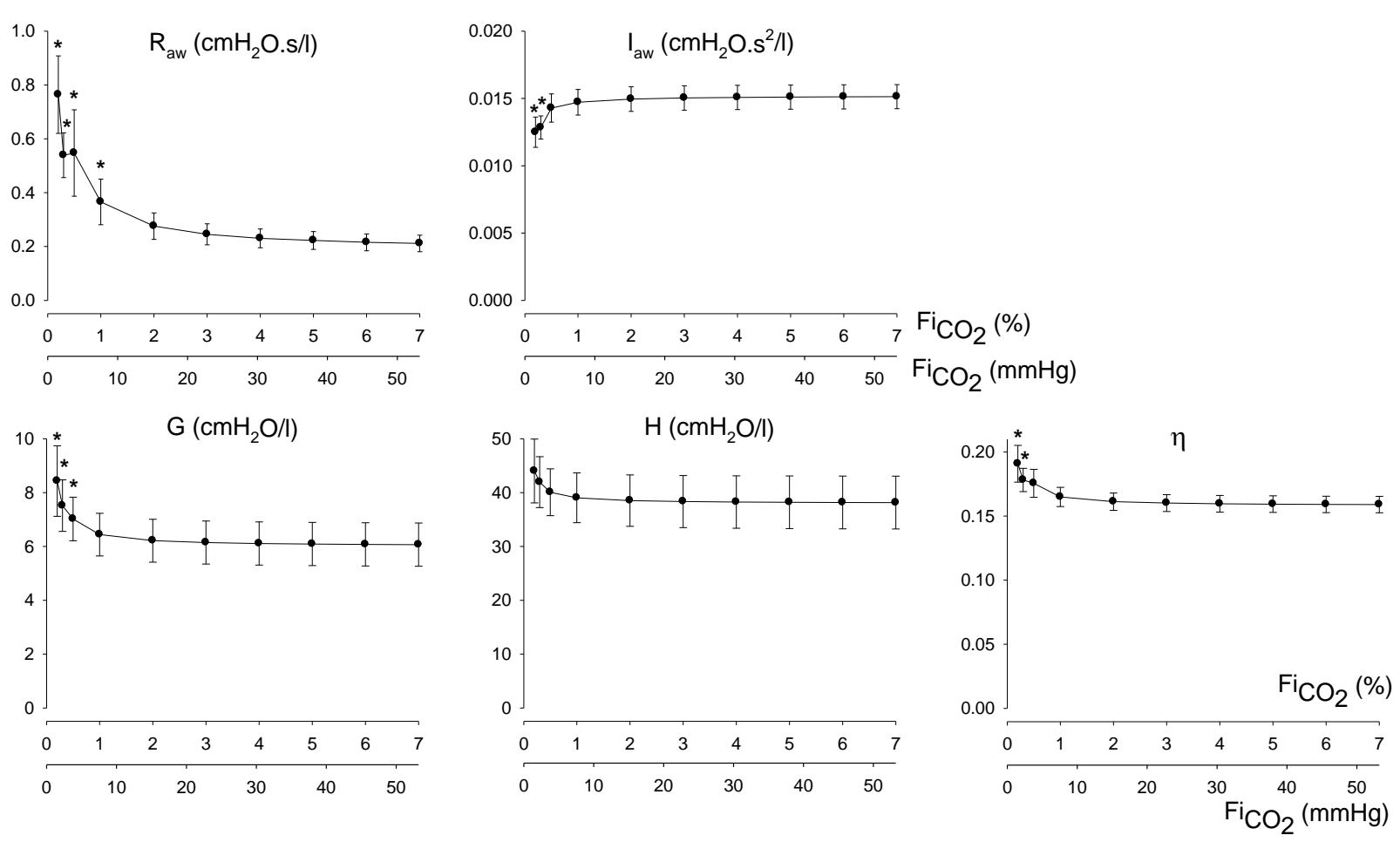

Figure 6. Group means $\pm S E(n=8)$ for the airway and lung parenchymal mechanical parameters at different levels of $\mathrm{Fi}_{\mathrm{CO}_{2}}$. $R_{\text {aw }}$ : airway resistance; $I_{a w}$ : airway inertance; $G$ : lung parenchymal damping; $H$ : lung parenchymal elastance; $\eta$ : tissue hysteresivity; $\mathrm{Fi}_{\mathrm{CO}_{2}}$ : fraction of inspired carbon dioxide. ${ }^{*} p<0.05$ vs. the values obtained under normocapnia $\left(\mathrm{Fi}_{\mathrm{CO}_{2}}=4 \%, 30.4 \mathrm{mmHg}\right)$.

This analysis revealed a markedly elevated $\mathrm{R}_{\mathrm{aw}}(243.2 \pm 334.7 \%, p<0.05$ vs. normocapnia defined as $5 \%$ or $38 \mathrm{mmHg})$ at $\mathrm{Fi}_{\mathrm{CO}_{2}}$ levels $<1 \%(7.6 \mathrm{mmHg})$, associated with a smaller decrease in $\mathrm{I}_{\mathrm{aw}}(-17.2 \pm 25.0 \%, p<0.05)$ at lower $\mathrm{Fi}_{\mathrm{CO}_{2}}$ levels. As regards the lung parenchymal parameters, $G$ and $\eta$ were moderately elevated $(38.4 \pm 63 \%$ and $22.5 \pm 2.7 \%$, respectively; $p<0.05$ for both) at low $\mathrm{Fi}_{\mathrm{CO}_{2}}$, whereas no significant changes occurred in $\mathrm{H}$ $(15.2 \pm 21.5 \%$; NS $)$ throughout the study protocol. There were no detectable alterations in $\mathrm{R}_{\mathrm{aw}}, \mathrm{I}_{\mathrm{aw}}, \mathrm{G}, \mathrm{H}$ and $\eta$ in the presence of alveolar hypercapnia. 


\subsection{Effects of systemic hypercapnia and acidosis on the mechanics of the pulmonary system}

The airway and lung tissue mechanical parameters determined before and after systemic acidosis, and the subsequent effects of atropine, are demonstrated in Figure 7 in the experiments performed on dogs in vivo. $\mathrm{R}_{\mathrm{aw}}$ and $\mathrm{I}_{\mathrm{aw}}$ were markedly and statistically significantly increased ( $p<0.001$ for both) in the presence of systemic hypercapnia and acidosis. Further, the administration of atropine counteracted this rise in $\mathrm{R}_{\mathrm{aw}}$ statistically significantly, whereas atropine had no effect on the elevated $I_{a w}$. Systemic acidosis induced mild, but statistically significant increases in $\mathrm{G}(p=0.02)$ and $\mathrm{H}(p<0.001)$, which were not affected by the administration of atropine.
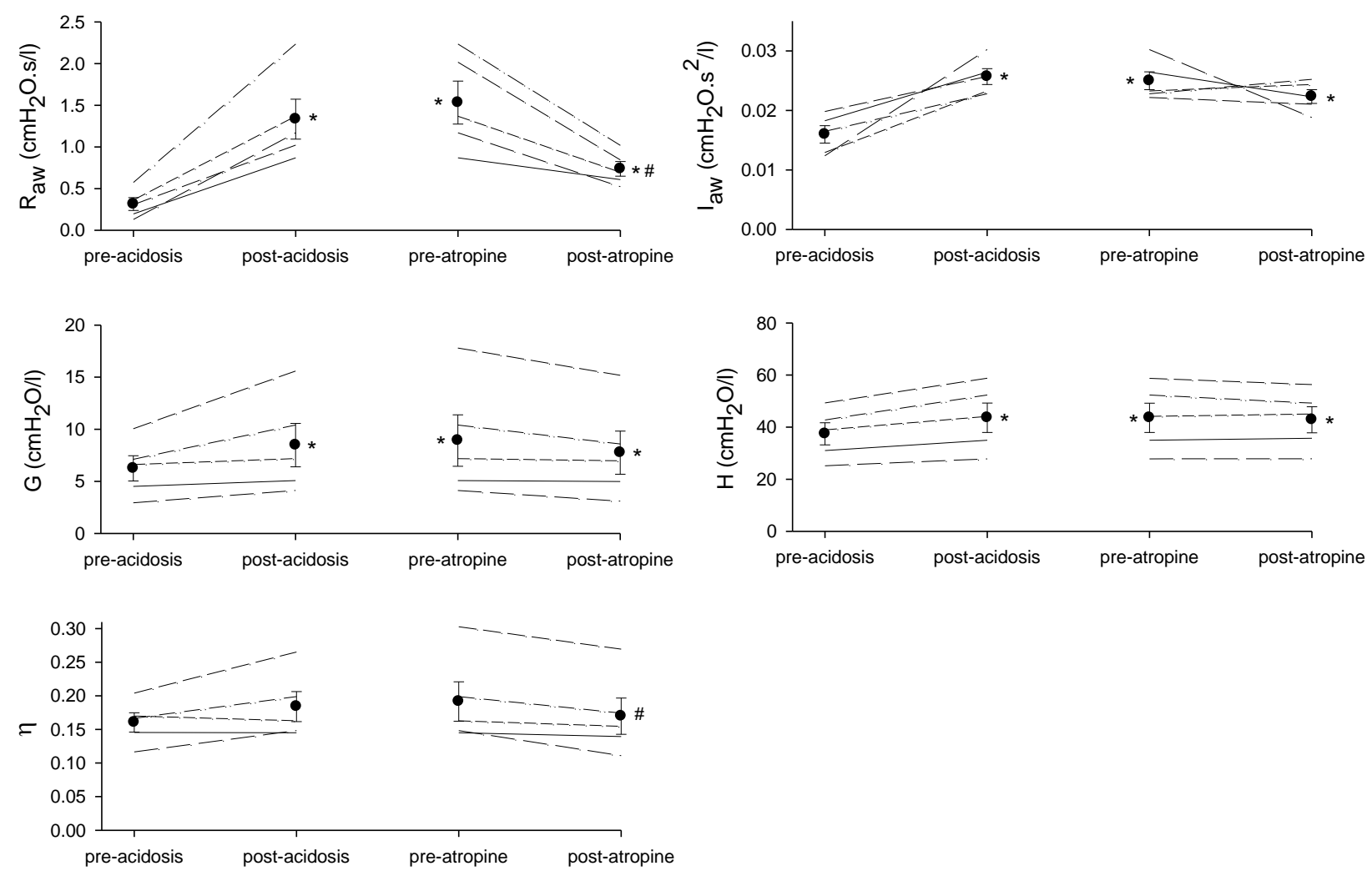

Figure 7. Airway and lung tissue mechanical parameters before and after systemic acidosis, and before and after administration of atropine, for the individual animals $(n=5$, lines), and as group means $\pm S E($ symbols). $R_{a w}$ : airway resistance; $I_{a w}$ : airway inertance; G: lung parenchymal damping; H: lung parenchymal elastance; $\eta$ : tissue hysteresivity. ${ }^{*} p<0.05$ vs. the values obtained before acidosis, ${ }^{*} p<0.05$ vs. pre-and post-atropine. 


\subsection{Effects of volatile anaesthetic agents on the airway and pulmonary parenchymal mechanics}

Figure 8 shows the percentage changes in the basic airway and lung tissue mechanical parameters in all groups of isolated perfused rat lungs. The basic airway tone was markedly and statistically significantly decreased by desflurane $\left(-31.2 \pm 3.8 \%\right.$ change in $\left.\mathrm{R}_{\mathrm{aw}}\right)$ and sevoflurane $\left(-18.0 \pm 4.5 \%\right.$ change in $\left.\mathrm{R}_{\mathrm{aw}}\right)$ administration, whereas halothane and isoflurane did not have a statistically significant effect on $\mathrm{R}_{\mathrm{aw}}(-3.3 \pm 5.1 \%$ and $-8.6 \pm 2.4 \%$, respectively). $\mathrm{I}_{\mathrm{aw}}$ was significantly higher during the administration of desflurane, while the other volatile agents had no effect on this parameter. None of the volatile agents exerted a significant effect on the baseline levels of the parenchymal mechanical parameters $\mathrm{G}$ and $\mathrm{H}$, and $\eta$.
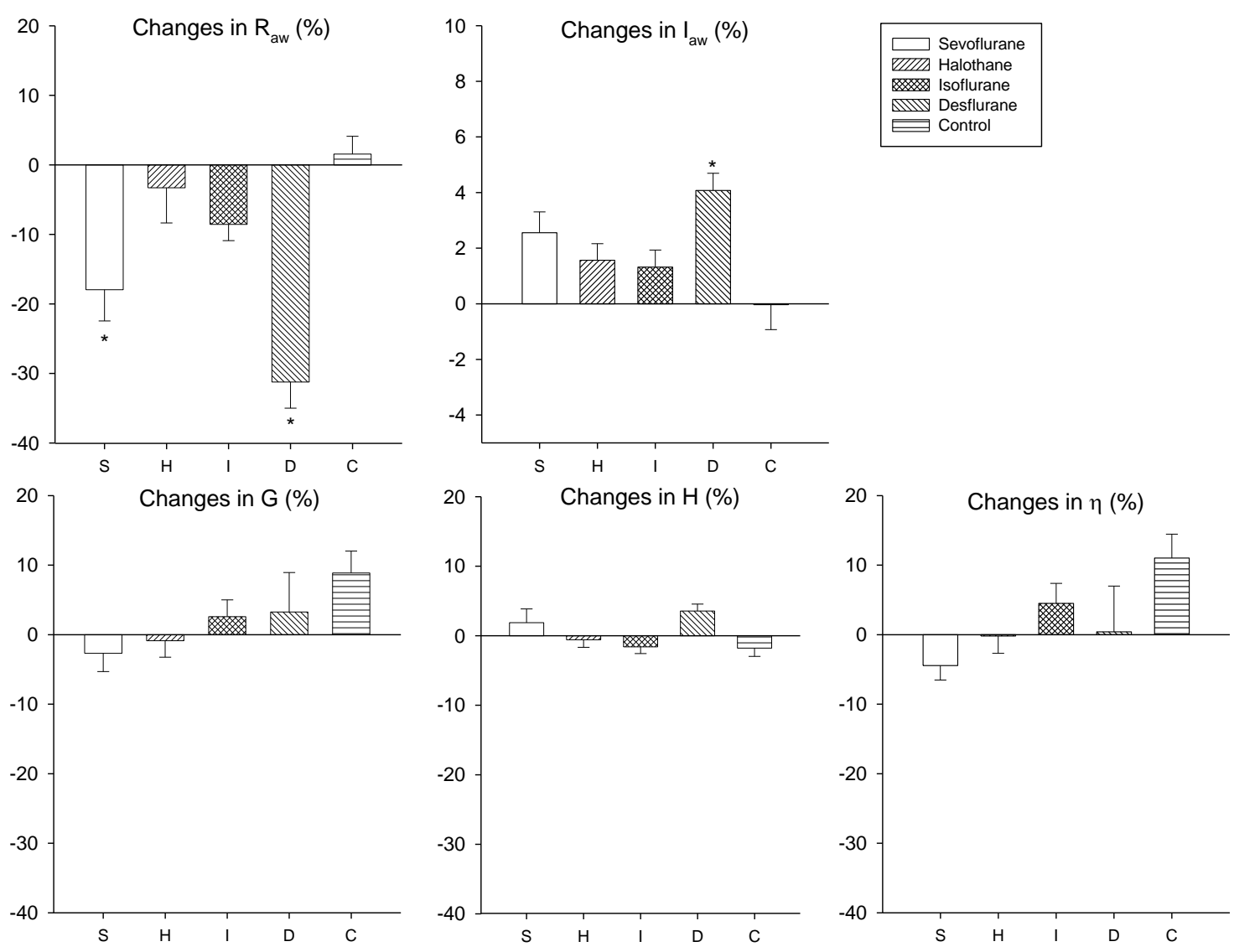

Figure 8. Changes in the baseline values of airway resistance $\left(R_{a w}\right)$, airway inertance $\left(I_{a w}\right)$, tissue damping coefficient $(G)$, tissue elastance $(H)$ and tissue hysteresivity $(\eta)$ following volatile agent administration. Values (mean and SE) are represented as relative changes from the control condition. C: control group; D: desflurane group; H: halothane group; I: isoflurane group; S: sevoflurane group. ${ }^{*} p<0.05$ vs. the control group. 


\subsection{Prevention of acetylcholine-induced changes in lung mechanics by volatile anaesthetic agents}

Figure 9 illustrates the results of airway and parenchymal mechanical parameters under the control conditions $(\mathrm{C} 1$ and $\mathrm{C} 2)$ and following the administration of the two different concentrations of ACh. In all groups, ACh induced statistically significant increases in $\mathrm{R}_{\mathrm{aw}}$ and $\mathrm{G}$ as compared with the control conditions. Further, comparison of the ACh-induced increases in $\mathrm{R}_{\mathrm{aw}}$ in the protocol groups revealed that sevoflurane and desflurane markedly and significantly inhibited the ACh-induced bronchoconstriction. Desflurane displayed the strongest effect; sevoflurane afforded less, but still significant, protection; the protective potentials of isoflurane and halothane did not reach the level of statistical significance. With regard to the lung parenchymal parameters, the ACh-induced elevations in $\mathrm{G}$ were slightly attenuated by all of the volatile anaesthetics; these minor effects were not statistically significant. In agreement with previous findings following the iv administration of $\mathrm{MCh}$ in $v_{i v o}{ }^{72}$, the values of $\mathrm{H}$ remained at the baseline level throughout the study protocol.
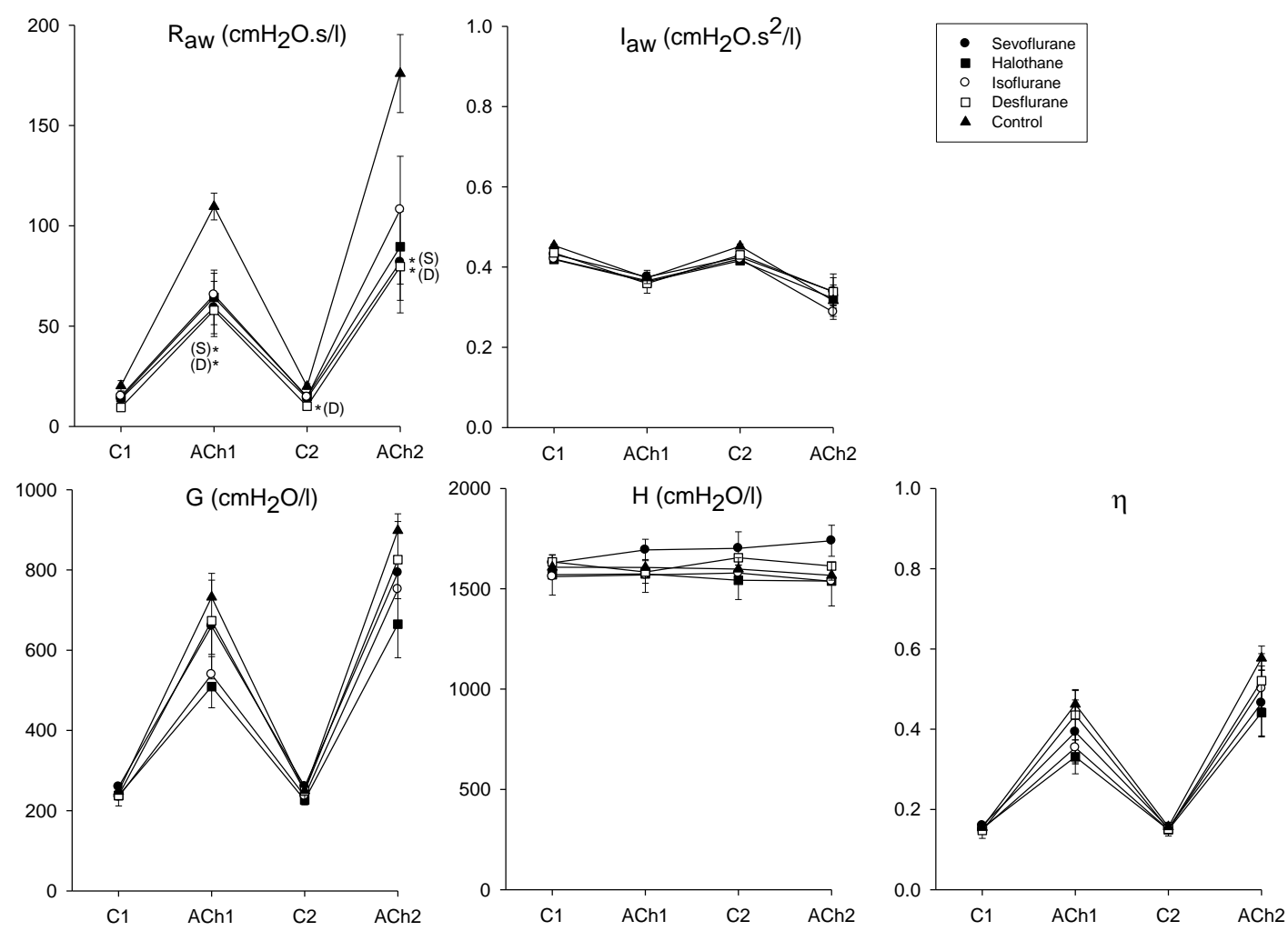

Figure 9. Parameters of resistance $\left(R_{a w}\right)$, airway inertance $\left(I_{a w}\right)$, tissue damping coefficient $(G)$, tissue elastance $(H)$ and tissue hysteresivity $(\eta)$ under baseline conditions $(C 1$ and $C 2)$ and following the administration of two different concentrations of acetylcholine (ACh) (ACh1: acetylcholine dose of $100 \mu \mathrm{g} / \mathrm{kg}$; ACh2: acetylcholine dose of $200 \mu \mathrm{g} / \mathrm{kg}$ ) in all experimental groups. C: control group; D: desflurane group; H: halothane group; I: isoflurane group; S: sevoflurane group. *p $<0.05$ vs. the control group. 
To further characterize the effects of the volatile agents on the enhanced airway tone obtained at different doses of ACh administration, we calculated the ratio of the changes in the mechanical parameters in the presence of the volatile agent and in the absence of the volatile agent. These relationships, expressed as percentage differences between the conditions (i.e. with and without volatile agent) are outlined in Figures 10 and 11. Noteworthy and statistically significant degrees of inhibition of the ACh-induced bronchoconstriction were observed following sevoflurane, desflurane and isoflurane administration, whereas the effects of halothane were considerably smaller. The presence of the volatile agents did not have a significant effect on the ACh-induced changes in $\mathrm{G}$ and $\mathrm{H}$.
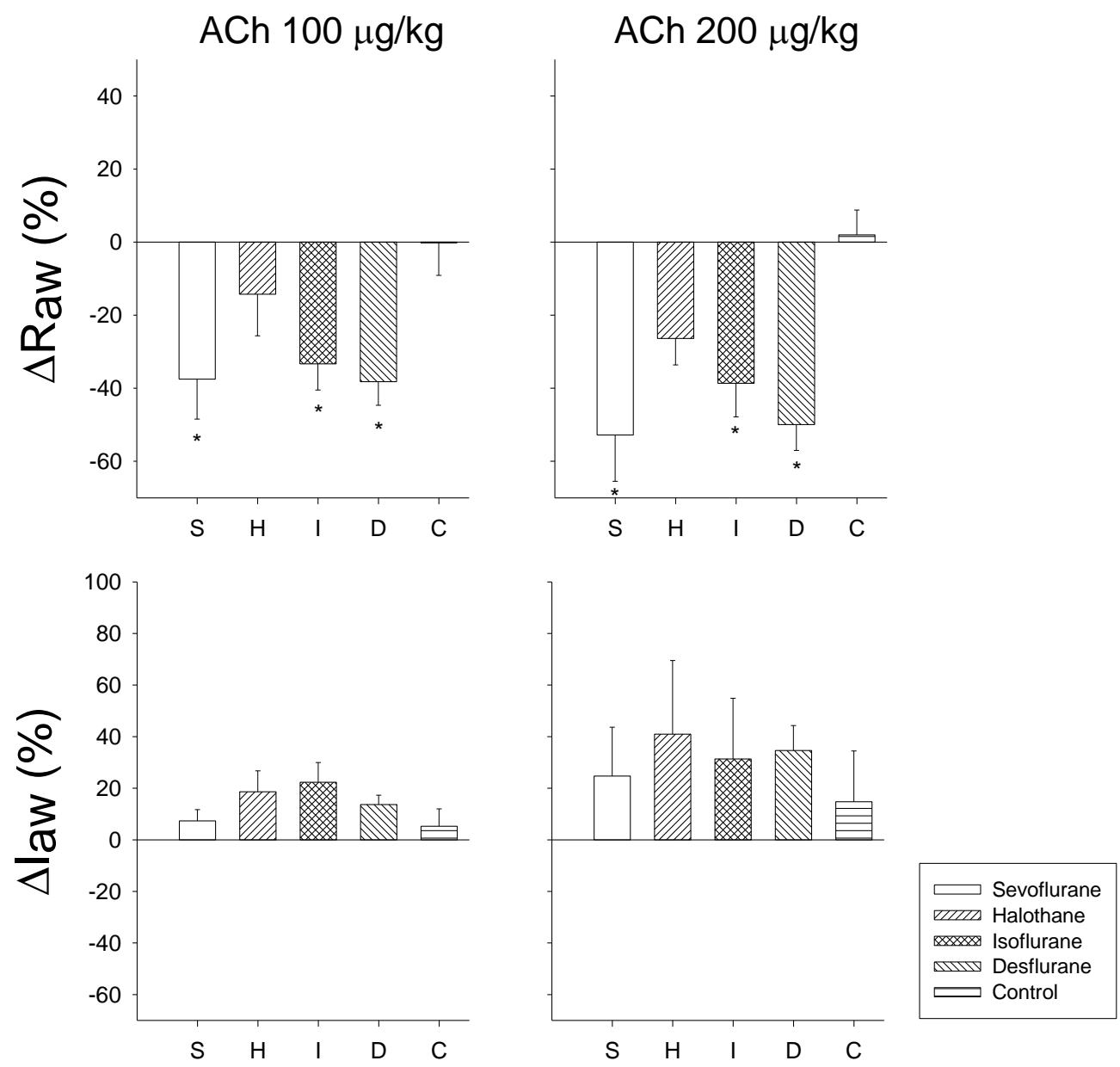

Figure 10. Relative changes in airway resistance $\left(R_{a w}\right)$ and airway inertance $\left(I_{a w},\right)$ between the conditions (i.e. with and without volatile anaesthetics) following the administration of two different concentrations of ACh (ACh1: acetylcholine dose of $100 \mu \mathrm{g} / \mathrm{kg}$; ACh2: acetylcholine dose of $200 \mu \mathrm{g} / \mathrm{kg}$ ) in all experimental groups. S: sevoflurane group; H: halothane group; I: isoflurane group; D: desflurane group; C: control group. Values (mean and SE) are represented as relative changes from the control condition. ${ }^{*} p<0.05$ vs. the control group. 

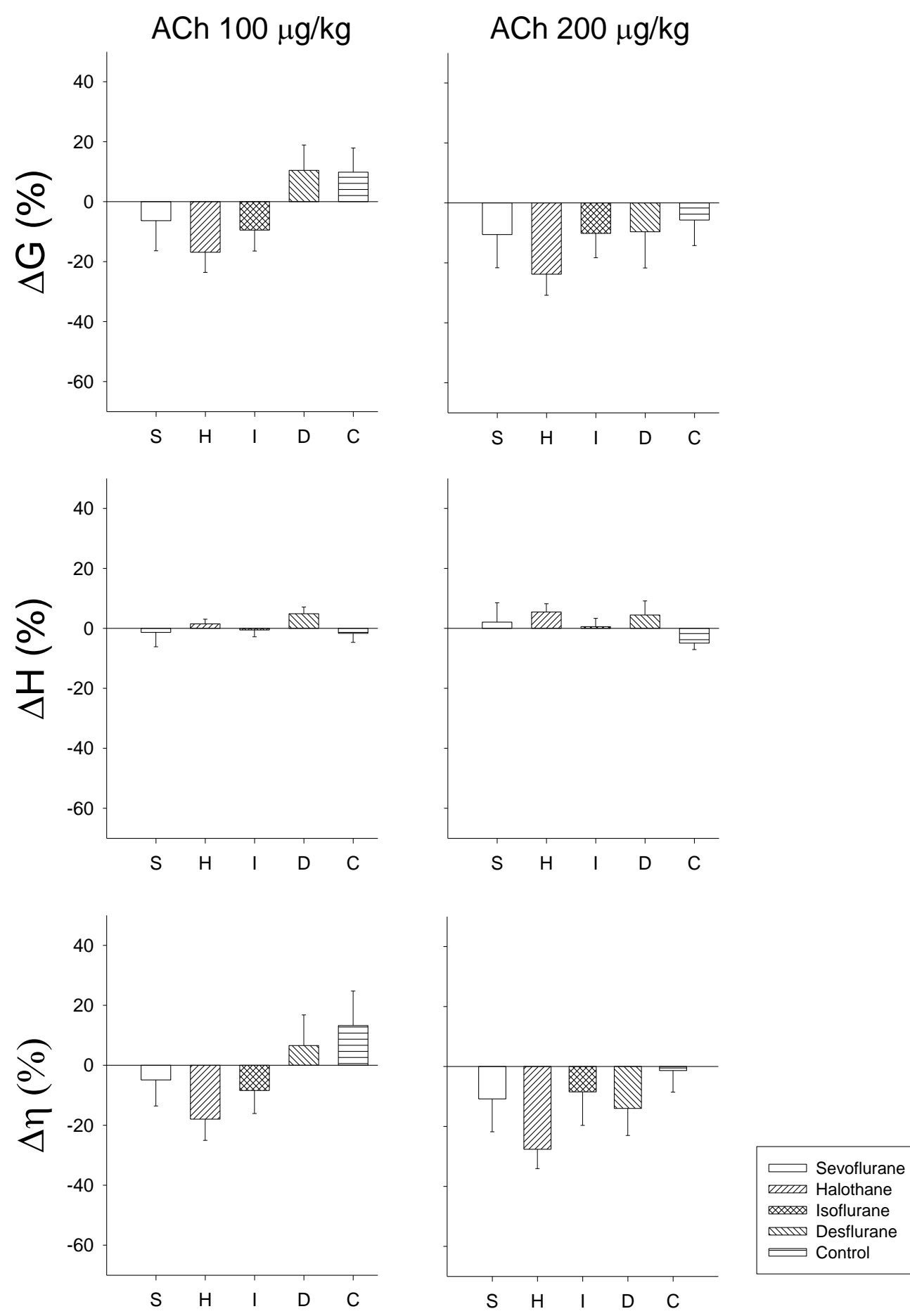

Figure 11. Relative changes in tissue damping $(G)$, tissue elastance $(H)$ and tissue hysteresivity $(\eta)$; between the conditions (i.e. with and without volatile anaesthetics) following the administration of two different concentrations of ACh (ACh1: acetylcholine dose of $100 \mu \mathrm{g} / \mathrm{kg}$; ACh2: acetylcholine dose of $200 \mu \mathrm{g} / \mathrm{kg}$ ) in all experimental groups. S: sevoflurane group; H: halothane group; I: isoflurane group; D: desflurane group; C: control group. Values (mean and SE) are represented as relative changes from the control condition. ${ }^{*} p<0.05$ vs. the control group. 


\section{Discussion}

Besides the neural, humoral mechanisms participating in the regulation of global lung ventilation, the experimental models included in the present thesis revealed that $\mathrm{CO}_{2}$ plays an important role in altering regional lung ventilation, and volatile anaesthetics decrease the elevated smooth muscle tone of the airways. The results also demonstrated that alterations of the endogenous $\mathrm{CO}_{2}$ level (intra-alveolar or systemic) or the presence of an exogenous gas, such as a volatile anaesthetic agent, have the potential to modulate the pulmonary mechanical properties.

The results of the studies included in the present thesis revealed that $a$ ) the different levels of intra-alveolar $\mathrm{CO}_{2}$ and the induction of systemic hypercapnia and acidosis alter the lung mechanical parameters under in vivo conditions during a $\mathrm{CPB}$, and $b$ ) shed light on the protective abilities of the currently used volatile agents against ACh-induced bronchoconstriction at an organ level under ex vivo conditions.

\subsection{Effects of alveolar hypocapnia and hypercapnia on the pulmonary mechanics}

We investigated the alterations in the airway and lung parenchymal mechanical properties when different levels of $\mathrm{CO}_{2}$ were maintained in the alveoli and in the systemic circulation. The application of extracorporeal circulation in the experimental design in openchest dogs allowed the manipulation of intra-alveolar $\mathrm{CO}_{2}$ levels in a wide range to establish a dose-response curve. The current experiments revealed the potential of alveolar hypocapnia to increase the airway tone markedly, with minor alterations in the pulmonary tissue parameters. The dose-response curve of $\mathrm{R}_{\mathrm{aw}}$ to $\mathrm{CO}_{2}$ revealed that, instead of a gradual increase in the bronchial tone, there was a sharp elevation in $\mathrm{R}_{\mathrm{aw}}$ at very low alveolar $\mathrm{CO}_{2}$ levels $(\leq 1 \%$ or $\leq$ $7.6 \mathrm{mmHg})$.

Our study was designed to characterize the effects of $\mathrm{CO}_{2}$ through wide-ranging changes of its concentration in the alveolar gas or in the blood in the systemic circulation, while the neurohormonal control was maintained intact. Utilization of a CPB was ideal for these purposes, since this approach permits not only the investigation of severe alveolar hypocapnia, but also independent manipulation of the alveolar and systemic $\mathrm{CO}_{2}$ levels. 
While the airway parameters $\mathrm{R}_{\mathrm{aw}}$ and $\mathrm{I}_{\mathrm{aw}}$ determined in our observations during normocapnia agree well with those reported previously in open-chest dogs, the current lung tissue parameters $\mathrm{G}$ and $\mathrm{H}$ appear to be somewhat larger ${ }^{58,69}$. This discrepancy is most probably due to the lack of pulmonary circulation in the present experiments, which compromises the lung tissue mechanics via loss of the tethering effect exerted by the filled pulmonary capillaries ${ }^{73}$. However, this bias was independent of the alveolar or systemic $\mathrm{CO}_{2}$ levels, and thus the main findings of the present study are not affected by this phenomenon.

A number of previous in vivo or ex vivo studies have revealed the constrictor response of the lungs to alveolar hypocapnia. The bronchoconstrictive effect of a moderately low airway $\mathrm{CO}_{2}$ concentration on the airway smooth muscle has been well established under in vivo conditions by manipulating the ventilation pattern or by occluding the pulmonary artery in various experimental models ${ }^{14,28,30,74}$. Study of the influence of severe hypocapnia $(<0.3 \%$ or $<2.3 \mathrm{mmHg} \mathrm{CO}_{2}$ ), which is feasible only under in vitro conditions ${ }^{31,75,76}$, further confirmed the development of severe airway narrowing while extremely low alveolar $\mathrm{CO}_{2}$ levels were maintained. Similarly to those earlier findings, our investigation demonstrated significant increases in $\mathrm{R}_{\mathrm{aw}}$ in response to decreases of the level of alveolar $\mathrm{CO}_{2}$. These changes were associated with small elevations in $G$ and $\eta$, and mild decreases in $I_{a w}$. Since this pattern of change in the lung mechanical parameters was manifested during airway constriction with marked ventilation heterogeneities ${ }^{77}$, it may be concluded that alveolar hypocapnia exerts constrictions on both the central (leading to marked elevations in $\mathrm{R}_{\mathrm{aw}}$ ) and the peripheral airways (leading to ventilation heterogeneities reflected by apparent increases in $\eta$ and decreases in $\left.I_{a w}\right)$.

The results relating to the effects of alveolar hypercapnia on the lung mechanics are more conflicting. Alveolar hypercapnia has been reported to elevate ${ }^{78-80}$, decrease ${ }^{31,81,82}$, or cause no changes ${ }^{29}$ in the total lung resistance $\left(R_{L}\right)$. The results of our study, obtained under well-controlled conditions, corroborate the latter earlier findings by demonstrating neutral effects of alveolar hypercapnia on the lung mechanics.

As far as we are aware, there has been only one previous in vivo study in which the changes in lung mechanical parameters were evaluated by measuring lung interrupter resistance $\left(\mathrm{R}_{\text {int }}\right)$ during wide-ranging alterations in the level of intra-alveolar $\mathrm{CO}_{2}{ }^{30}$. Our observations indicating an increase in $\mathrm{R}_{\mathrm{aw}}$ correspond well with those obtained previously in 
the $\mathrm{R}_{\text {int }}$ range where the intra-alveolar and intra-arterial $\mathrm{CO}_{2}$ overlap. Nevertheless, in consequence of the presence of a pulmonary circulation in the previous experiments, the minimum alveolar $\mathrm{CO}_{2}$ partial pressure attained was $\sim 20 \mathrm{mmHg}$ (which corresponds to $2.6 \%$ in the present study). Thus, the noteworthy feature of the dose-response curve in $R_{a w}$ to the altered intra-alveolar $\mathrm{CO}_{2}$, the sharp increase in this parameter when $\mathrm{Fi}_{\mathrm{CO}_{2}}$ decreased to $1 \%$ $(7.6 \mathrm{mmHg})$, remained undetected in that previous study. This highly non-linear feature of the dose-response curve may be of importance in the mechanisms of adaptation of the lungs to altered conditions via regulation of the ventilation distribution.

Hyperventilation initiated regularly by the central nervous system to compensate hypoxaemia may reduce the intra-alveolar $\mathrm{CO}_{2}$, but this decrease cannot reach a concentration of $<2 \%(15.2 \mathrm{mmHg})^{30}$. Our data indicate no detectable bronchoconstriction under these conditions (Figure 6), which is a sensible physiological response as the lung function remains normal to maintain optimum gas exchange. Intra-alveolar $\mathrm{CO}_{2}$ concentrations of $<1 \%$ (7.6 $\mathrm{mmHg}$ ) can develop in lung regions with no or only a severely diminished pulmonary perfusion, such as those observed following pulmonary embolism. Acute blockade of pulmonary perfusion by pulmonary embolism (clots, gas, etc. embolism) results in increased alveolar dead space ventilation of the affected non-perfused pulmonary region. Our findings demonstrate that the pulmonary embolism and the subsequent local alveolar hypocapnia also result in the activation of a local reflex mechanism leading to the redirection of the alveolar ventilation from the non-perfused regions to the units with normal perfusion ${ }^{83}$. Such a regional bronchoconstriction that develops due to alveolar hypocapnia ${ }^{14,84-88}$ is therefore a compensatory physiological response, which can decrease the mismatch between ventilation and perfusion. Thus, the acute pulmonary embolism can decrease not only the pulmonary capillary, but additionally the alveolar surface. On the other hand, this parallel decline in the pulmonary perfusion and ventilation can protect against hypoxaemia, but can be accompanied by an elevated systemic $\mathrm{CO}_{2}$ level. Our findings further demonstrate that this systemic hypercapnia contributes to the localized bronchoconstriction in order to prevent the affected lung regions from "reopening", and hence to protect from the aggravation of the ventilationperfusion mismatch. This phenomenon may be regarded as a synergistic pathophysiological constrictor ability of the affected non-perfused airways initiated by the direct effects of the reduced intra-alveolar and the indirect effects of the elevated systemic $\mathrm{CO}_{2}$ concentration. 
This mechanism is expected to be most effective if it affects the small airways in the lung periphery. Indeed, the involvement of peripheral airways in hypocapnia-induced bronchoconstriction is substantiated by the proportionally greater increases in $G$ than in $H$ leading to elevations in $\eta$, a hallmark feature of the presence of heterogeneous peripheral airway constriction with the development of ventilation heterogeneities ${ }^{43}$.

\subsection{Changes in the mechanics of the pulmonary system during systemic hypercapnia and acidosis}

In contrast with the neutral effects of alveolar hypercapnia on the lung mechanics observed in dogs in vivo, hypercapnia induced in the systemic circulation generated significant elevations in both the resistive and inertive airway parameters and the parenchymal resistance and elastance values. The adverse changes in the airway mechanics under these conditions were inhibited by elimination of the vagal activity with atropine. However, vagal blockade with atropine did not reverse the deteriorated lung parenchymal mechanics in the presence of systemic hypercapnia and acidosis.

Systemic acidosis and hypercapnia with alveolar normocapnia can exist only in the presence of a bronchial circulation without pulmonary blood flow (as is the case during a $\mathrm{CPB}$ ), for otherwise the elevated systemic $\mathrm{CO}_{2}$ would consequently appear in the alveoli. Vice versa, the elevated $\mathrm{Fi}_{\mathrm{CO}_{2}}$ during a $\mathrm{CPB}$ has no direct systemic effects, as the interrupted pulmonary circulation cannot transmit the $\mathrm{CO}_{2}$ induced into the systemic circulation. We elevated $\mathrm{PET}_{\mathrm{CO}_{2}}$ levels in order to minimize the time necessary to reach a new equilibrium. There were no obvious temporal changes in the lung mechanical parameters during the experiments, and sufficient time was allowed for the animals to reach equilibrium in the lungs and the systemic circulation after establishing each $\mathrm{CO}_{2}$ level. Although the randomized order of the $\mathrm{CO}_{2}$ levels would have decreased the potential temporal effects in the experiments, the increasing order of $\mathrm{PET}_{\mathrm{CO}_{2}}$ was not likely to affect our findings significantly. While the bronchoprotecting potential of propofol might have blunted the constrictor effects of $\mathrm{CO}_{2}{ }^{89}$, our dose was much lower than that proved to be effective against MCh-induced bronchoconstriction.

In the present study, systemic acidosis via systemic hypercapnia was produced by supplying $\mathrm{CO}_{2}$ into the extracorporeal circulation (into the oxygenator). An elevated level of 
systemic $\mathrm{CO}_{2}$ may exert its pulmonary effects via direct and indirect pathways. As concerns the direct effects of excess systemic $\mathrm{CO}_{2}$, it most probably reaches the cells of the tracheobronchial tree in the terminal bronchioles, via the bronchial circulation, and then gains direct access to the proximal airway smooth muscle cells. Previous studies on denervated bronchi indicated a relaxation of the airway smooth muscle, suggesting the presence of direct $\mathrm{CO}_{2}$-mediated bronchodilatation ${ }^{78}$. This discrepancy suggests that, in our observations, the direct bronchodilation activity of $\mathrm{CO}_{2}$ was overwhelmed by vagally controlled indirect effects of systemic hypercapnia. Indeed, unlike the conflicting results concerning the pulmonary effects of alveolar hypercapnia, there is a consensus in the literature on the bronchoconstrictor potential of systemic hypercapnia when the neural control of the lungs remains intact ${ }^{29,31,78,79}$. The inhibition of ACh release from the vagal efferent nerve endings on the airways by the administration of atropine almost fully reversed the increases in $\mathrm{R}_{\mathrm{aw}}$, while the elevations in the lung tissue parameters were essentially unaffected. This points to a more pronounced role of the vagus nerve in regulating the central airways following systemic $\mathrm{CO}_{2}$ changes, which accords well with earlier results demonstrating the primary site of vagal control in the central conducting airways ${ }^{90}$.

\subsection{Effects of volatile anaesthetic agents on the mechanical properties of the lung}

Bronchospasm is a potential complication in any patient undergoing general anaesthesia. Tracheal intubation or any other manipulation in the airways, e.g. a suction manoeuvre, may induce severe bronchoconstriction in patients with asthma or chronic obstructive pulmonary disease. Administration of volatile anaesthetics prior to physical airway stimulation may be valuable in patients with airway susceptibilities.

A number of previous in vivo experimental or clinical studies have described the influence of the commonly used volatile anaesthetics on the bronchial smooth muscle tone. Conflicting data have been reported concerning the ability of desflurane to affect the airway tone. Most of the clinical studies have indicated a high incidence of airway irritation during the administration of desflurane (coughing, breath-holding, excessive secretion and laryngospasm) $)^{91,92}$ and a similar potency was observed under experimental conditions ${ }^{42}$. In contrast, in a few clinical $^{93}$ and experimental studies ${ }^{94}$, desflurane exhibited a marked 
bronchodilator potential. The reasons for these controversial findings have not been fully elucidated. It is noteworthy, however, that in vitro studies have consistently demonstrated the bronchodilator effect of desflurane ${ }^{95-99}$, as for other volatile anaesthetics ${ }^{95-101}$. Analogously to our findings, desflurane and sevoflurane have been shown to exert more potent bronchodilatator effects than those of halothane in isolated airway smooth muscles ${ }^{95,99}$ and in isolated tracheal rings ${ }^{98}$. In contrast, other ex vivo studies have indicated that halothane has a greater relaxing effect on the airway smooth muscle than sevoflurane, isoflurane or desflurane ${ }^{96}$. Although the reasons for these conflicting results are not totally clear, all of these previous in vitro studies consistently demonstrated the bronchodilator potential of desflurane.

The relaxation properties of the volatile anaesthetic agents applied commonly in clinical practice were compared in our study in an isolated perfused rat lung model. This experimental setting, combined with a low-frequency forced oscillation technique, allows a separate assessment of the airway and parenchymal mechanics in the absence of neural control of the lungs and without the confounding influence of the alterations in pulmonary haemodynamics induced by bronchoactive drug administration. The current experiments revealed the potential of desflurane and sevoflurane to decrease the basal airway tone, whereas isoflurane and halothane were ineffective in this regard.

Many previous studies have focused on the cellular mechanisms of action of volatile anaesthetics on airway smooth muscle cell cultures ${ }^{44,45}$ or isolated tracheal and/or bronchial rings ${ }^{95-100}$. The structural integrity of the lungs has been lost in such investigations, which makes it difficult to extrapolate these findings to an organ level. The results obtained under in vivo experimental conditions, on the other hand, are influenced by numerous confounding effects of systemic hormonal and neurogenic origin. The isolated ex vivo rat lung model applied in the present study offers ideal conditions under which to investigate the effects of volatile anaesthetics on the airway tone under baseline conditions and in the presence of airway constriction at an organ level. Furthermore, excised lungs are an ideal model on which to investigate the direct effects of bronchoactive agonists in the absence of reflex mechanisms involving neural pathways and without the biasing effects of acutely released humoral mediators. This setting permits the maintenance of stable haemodynamic conditions, and also a separate assessment of the changes in the airway and parenchymal mechanics. 


\subsection{Protective potential of volatile anaesthetic agents against acetylcholine- induced bronchoconstriction}

An important feature of the present study is the administration of the constrictor agent into the pulmonary circulation. No previous studies have characterized the changes in the airway and the lung parenchymal properties in small laboratory animals when the contractile agonist is administered via the pulmonary circulation. This route of the bronchoconstrictor agonist supplies the lung periphery, and it therefore offers a possibility to challenge the terminal airways and the alveolar contractile apparatus. The absence of systemic circulation in the isolated lung model applied in the present experimental setting avoids challenging the large conducting airways. This model resembles a human transplanted lung with no bronchial circulation and innervation exposed to a constrictor challenge via the circulation.

Many of the procedures used in anaesthetic practice may involve direct stimulation of the muscarinic receptors (via mechanical stimulation of the airways, i.e. tracheal intubation, bronchoscopy or bronchial suction), resulting in cholinergic-mediated bronchospasm. As ACh acts as a physiological ligand on the muscarinic receptors, adverse changes in lung function were induced by generating a spastic condition following stimulation of the muscarinic receptors.

As most previous studies applied global parameters to express the lung responses to volatile anaesthetic agents ${ }^{101-105}$, the relative contributions of the airways and the lung parenchyma to the lung response to ACh-induced bronchospasm cannot be distinguished. In the present study, the low-frequency forced oscillatory technique and the model-based evaluation of the impedance data were applied to separate the airway and the lung parenchymal mechanical properties. This technique has been validated $^{77}$ and used successfully in small rodents ${ }^{73,94}$ and in isolated perfused rat lungs ${ }^{70,73}$, and has been shown to furnish selective parameters for the airway and parenchymal mechanics and to allow reliable quantification of the changes in these compartments. The airway and parenchmyal mechanical parameters under baseline conditions are in excellent agreement with those obtained previously $^{70,73}$.

In the present study, all of the currently used volatile agents exerted a marked protective effect against bronchoconstriction in the presence of an increased airway tone induced by the administration of ACh into the pulmonary circulation. The efficacy of this 
bronchoprotective potential of the volatile agents was not affected by the magnitude of the constrictor stimuli. The ACh-induced increases in the lung tissue parameter related to parenchymal damping were not prevented by any of the volatile anaesthetics applied in the current investigations.

The observations of our study confirm the marked protective properties of desflurane against the airway constriction induced by cholinergic stimulation of the muscarinic receptors. Our finding that desflurane prevents ACh-induced bronchoconstriction may suggest that the humoral or neural pathways present in vivo are responsible for the lower protective potential of desflurane against airway constriction.

The results obtained in our study demonstrate that ACh induced marked increases in $\mathrm{R}_{\mathrm{aw}}$ and $\mathrm{G}$, but with no significant effects on $\mathrm{H}$. This pattern of change in the lung mechanical parameters indicates that $\mathrm{ACh}$ induces heterogeneous airway constriction with marked ventilation heterogeneities, this phenomenon giving rise to changes in $G$ rather than altered intrinsic parenchymal mechanics ${ }^{77}$. We observed the potential of these volatile anaesthetics to prevent increases in $\mathrm{R}_{\mathrm{aw}}$, while they were all ineffective in inhibiting the ACh-induced increases in $\mathrm{G}$. The inability of the volatile agents to prevent the increases in $\mathrm{G}$ is in contrast with previous findings in vivo ${ }^{94,103}$. The fundamental difference in the site of action of the cholinergic stimulation may explain this controversy. While the muscarinic receptors are stimulated in the whole lung during intravenous challenges under in vivo conditions, ACh administered into the pulmonary circulation in isolated perfused lungs reaches primarily the receptors located in the lung periphery, leading to a heterogeneous constriction of more distal airways. Under these conditions, the volatile agents are able to prevent the overall airway constriction, while the stability of $\mathrm{G}$ indicates that they are not effective in reducing the ventilation heterogeneities.

\section{Summary and Conclusions}

The studies included in the present thesis focused on achieving a better understanding of the pulmonary effects of the different levels of intra-alveolar and systemic $\mathrm{CO}_{2}$ and common volatile anaesthetic agents under various conditions that occur during routine anaesthetic practice. The mechanical properties of the lungs were partitioned into airway and 
parenchymal components by a model-based evaluation of the low-frequency pulmonary input impedance spectra measured by a forced oscillation technique.

The separate assessment of the airway and pulmonary parenchymal responses revealed the following findings:

a) Alveolar hypercapnia with the maintenance of a physiological $\mathrm{CO}_{2}$ level in the systemic circulation exerted no effect on the lung mechanics.

b) In contrast, we highlighted that systemic hypercapnia and acidosis mainly generated central airway constriction, mediated primarily by the vagus nerve.

c) Decrease of the $\mathrm{CO}_{2}$ concentration in the intrapulmonary gas to below the physiological value had no detectable effect on the lung mechanics until a concentration of $\sim 2 \%(15.2 \mathrm{mmHg})$ was reached, whereas severe bronchoconstriction with marked ventilation heterogeneities in the lung periphery developed sharply when the intra-alveolar $\mathrm{CO}_{2}$ concentration was lowered to $<2 \%(15.2 \mathrm{mmHg})$. This biphasic feature of the dose-response curve is of importance as concerns decreases in the ventilation-perfusion mismatch via redirection of the airflow to the well-perfused lung areas from those lung regions where the pulmonary perfusion is severely compromised.

d) Constrictor provocation through the pulmonary circulation has a more peripheral effect than those observed previously following iv challenges performed in vivo. This finding can be explained by the absence of the bronchial circulation in our study, and may have implications in the clinical evaluation of the reactivity of transplanted lungs.

e) Desflurane and sevoflurane have the potential to decrease the basal airway smooth muscle tone, whereas isoflurane and halothane are ineffective in this regard on a denervated isolated perfused lung model.

f) All the currently used volatile agents exert a marked protective effect against AChinduced bronchoconstriction, desflurane and sevoflurane having the most potent inhibitory effects. These findings provide evidence that desflurane exerts relaxation activity on the airway smooth muscle that is similar to or even stronger than the activities of other common volatile anaesthetics at an organ level under ex vivo conditions. 


\section{Acknowledgements}

I would like to express my gratitude to both of my supervisors. I am grateful to my supervisor Ferenc Peták for his valuable guidance and for his support in my experimental work. His excellent advice, instructions and tutoring have been indispensable in my research activity. I am also very grateful to my supervisor Barna Babik, who introduced me to this research and clinical area. I also greatly appreciate his continuous guidance, his invaluable advice and wisdom, and his limitless trust.

I would like to express my appreciation to Professor Zoltán Hantos, who also introduced me to this research area. I am honoured to have received his selfless and invaluable generous help, which has had a fundamental influence on my research career, and also his essential philosophy, which represents perfectionism, and imaginative and precious reasoning.

My grateful thanks are due to Professor Walid Habre for his highly valuable help in my research and clinical career. I greatly appreciate his support, which has been so important during all these years.

I also wish to express my thanks to Professor Denis Morel and all the staff of the Anaesthesiological Investigation Unit at the University of Geneva, for their contribution, and especially to Fabienne, Manu and Sylvie. I extend my thanks to the staff of the Department of Anaesthesiology and Intensive Therapy of Cardiac Surgery and the staff of the Institute of Surgical Research, University of Szeged, for their excellent cooperation.

I shall always be grateful to my mother and my friends, Attila, Helga and Anna, for their continuous support in the most difficult days.

The work presented in this thesis was supported by a Swiss National Science Foundation Grant (No. 3200-064899.01 - Bern, Switzerland) and Hungarian Scientific Research Grants (OTKA K81179 and K67700 - Budapest, Hungary). 


\section{References}

1. Weibel E.R. Morphometry of the Human Lung. Springer-Verlag, Berlin 1963.

2. Belvisi MG. Overview of the innervation of the lung. Current opinion in pharmacology. 2002;2:211-215.

3. Barnes PJ. Modulation of neurotransmission in airways. Physiological reviews. 1992;72:699-729.

4. Barnes PJ. Neural control of human airways in health and disease. The American review of respiratory disease. 1986;134:1289-1314.

5. Partanen M, Laitinen A, Hervonen A, Toivanen M, Laitinen LA. Catecholamine- and acetylcholinesterase-containing nerves in human lower respiratory tract. Histochemistry. 1982;76:175-188.

6. Mak JC, Barnes PJ. Autoradiographic visualization of muscarinic receptor subtypes in human and guinea pig lung. The American review of respiratory disease. 1990;141:1559-1568.

7. Barnes PJ. Neural control of airway function: new perspectives. Molecular aspects of medicine. 1990;11:351-423.

8. Widdicombe JG. Autonomic regulation. i-NANC/e-NANC. Am J Respir Crit Care Med. 1998;158:S171-175.

9. Kneussl MP, Richardson JB. Alpha-adrenergic receptors in human and canine tracheal and bronchial smooth muscle. Journal of applied physiology: respiratory, environmental and exercise physiology. 1978;45:307-311.

10. Snashall PD, Boother FA, Sterling GM. The effect of alpha-adrenoreceptor stimulation on the airways of normal and asthmatic man. Clin Sci Mol Med. 1978;54:283-289.

11. Black JL, Salome CM, Yan K, Shaw J. Comparison between airways response to an alpha-adrenoceptor agonist and histamine in asthmatic and non-asthmatic subjects. $\mathrm{Br}$ J Clin Pharmacol. 1982;14:464-466.

12. Guyton AC, Hall JE. Textbook of Medical Physiology. Saunders Company, Philadelphia 2000.

13. Staub NC. Basic respiratory physiology. Churchill-Livingstone, New York 1991. 
14. Severinghaus JW, Swenson EW, Finley TN, Lategola MT, Williams J. Unilateral hypoventilation produced in dogs by occluding one pulmonary artery. Journal of applied physiology: respiratory, environmental and exercise physiology. 1961;16:5360.

15. Swenson ER, Graham MM, Hlastala MP. Acetazolamide slows $V_{\mathrm{A}} / \mathrm{Q}$ matching after changes in regional blood flow. Journal of applied physiology: respiratory, environmental and exercise physiology. 1995;78:1312-1318.

16. Swenson EW, Finley TN, Guzman SV. Unilateral hypoventilation in man during temporary occlusion of one pulmonary artery. The Journal of clinical investigation. 1961;40:828-835.

17. Domino KB, Emery MJ, Swenson ER, Hlastala MP. Ventilation heterogeneity is increased in hypocapnic dogs but not pigs. Respiration physiology. 1998;111:89-100.

18. Domino KB, Swenson ER, Polissar NL, Lu Y, Eisenstein BL, Hlastala MP. Effect of inspired $\mathrm{CO}_{2}$ on ventilation and perfusion heterogeneity in hyperventilated dogs. Journal of applied physiology: respiratory, environmental and exercise physiology. 1993;75:1306-1314.

19. Swenson ER, Robertson HT, Hlastala MP. Effects of inspired carbon dioxide on ventilation-perfusion matching in normoxia, hypoxia, and hyperoxia. Am J Respir Crit Care Med. 1994;149:1563-1569.

20. Swenson E, Domino KB, Hlastala MP. Physiological effects of oxygen and carbon dioxide on $\mathrm{V}^{\cdot} / \mathrm{Q}$ heterogeneity. In: Complexity in Structure and Function of the Lung (Edited by Hlastala, M. P. and Robertson, H. T.). Marcel Dekker, Inc., New York 1998;Chapter 17.:511-547.

21. Allgood RJ, Wolfe WG, Ebert PA, Sabiston DC, Jr. Effects of carbon dioxide on bronchoconstriction after pulmonary artery occlusion. Am J Physiol. 1968;214:772775.

22. Darke CS, Astin TW. Differential ventilation in unilateral pulmonary artery occlusion. Thorax. 1972;27:480-486.

23. Tisi GM, Wolfe WG, Fallat RJ, Nadel JA. Effects of $\mathrm{O}_{2}$ and $\mathrm{CO}_{2}$ on airway smooth muscle following pulmonary vascular occlusion. Journal of applied physiology: respiratory, environmental and exercise physiology. 1970;28:570-573. 
24. Brown SJ, Mundel T, Barnes M, Brown JA. Indirect measures of human vagal withdrawal during head-up tilt with and without a respiratory acidosis. The journal of physiological sciences : JPS. 2009;59:31-36.

25. Iscoe S, Fisher JT. Bronchomotor responses to hypoxia and hypercapnia in decerebrate cats. Journal of applied physiology: respiratory, environmental and exercise physiology. 1995;78:117-123.

26. Waldron MA, Fisher JT. Differential effects of $\mathrm{CO}_{2}$ and hypoxia on bronchomotor tone in the newborn dog. Respiration physiology. 1988;72:271-282.

27. Chapman RW, Danko G. Role of cholinergic, vagal reflexes on the bronchoconstrictor responses to histamine during carbon dioxide inhalation in conscious guinea-pigs. Pharmacol Res. 1990;22:133-141.

28. Coleridge HM, Coleridge JC, Banzett RB. II. Effect of $\mathrm{CO} 2$ on afferent vagal endings in the canine lung. Respiration physiology. 1978;34:135-151.

29. Green M, Widdicombe JG. The effects of ventilation of dogs with different gas mixtures on airway calibre and lung mechanics. J Physiol. 1966;186:363-381.

30. D'Angelo E, Calderini IS, Tavola $\mathrm{M}$. The effects of $\mathrm{CO}_{2}$ on respiratory mechanics in anesthetized paralyzed humans. Anesthesiology. 2001;94:604-610.

31. Ingram $\mathrm{RH}$, Jr. Effects of airway versus arterial $\mathrm{CO}_{2}$ changes on lung mechanics in dogs. Journal of applied physiology: respiratory, environmental and exercise physiology. 1975;38:603-607.

32. Lutchen KR, Kaczka DW, Suki B, Barnas G, Cevenini G, Barbini P. Low-frequency respiratory mechanics using ventilator-driven forced oscillations. Journal of applied physiology: respiratory, environmental and exercise physiology. 1993;75:2549-2560.

33. Brakensiek AL, Bergman NA. The effects of halothane and atropine on total respiratory resistance in anesthetized man. Anesthesiology. 1970;33:341-344.

34. Patterson RW, Sullivan SF, Malm JR, Bowman FO, Jr., Papper EM. The effect of halothane on human airway mechanics. Anesthesiology. 1968;29:900-907.

35. Colgan FJ. Performance of lungs and bronchi during inhalation anesthesia. Anesthesiology. 1965;26:778-785.

36. Fletcher SW, Flacke W, Alper MH. The actions of general anesthetic agents on tracheal smooth muscle. Anesthesiology. 1968;29:517-522. 
37. Habre W, Petak F, Sly PD, Hantos Z, Morel DR. Protective effects of volatile agents against methacholine-induced bronchoconstriction in rats. Anesthesiology. 2001;94:348-353.

38. von Ungern-Sternberg BS, Saudan S, Peták F, Hantos Z, Habre W. Desflurane but not sevoflurane impairs airway and respiratory tissue mechanics in children with susceptible airways. Anesthesiology. 2008;108:216-224.

39. Habre W, Scalfaro P, Sims C, Tiller K, Sly PD. Respiratory mechanics during sevoflurane anesthesia in children with and without asthma. Anesth Analg. 1999;89:1177-1181.

40. Scalfaro P, Sly PD, Sims C, Habre W. Salbutamol prevents the increase of respiratory resistance caused by tracheal intubation during sevoflurane anesthesia in asthmatic children. Anesth Analg. 2001;93:898-902.

41. von Ungern-Sternberg BS, Saudan S, Petak F, Hantos Z, Habre W. Desflurane but not sevoflurane impairs airway and respiratory tissue mechanics in children with susceptible airways. Anesthesiology. 2008;108:216-224.

42. Schutz N, Petak F, Barazzone-Argiroffo C, Fontao F, Habre W. Effects of volatile anaesthetic agents on enhanced airway tone in sensitized guinea pigs. British journal of anaesthesia. 2004;92:254-260.

43. Nakayama M, Kondo U, Murray PA. Pulmonary vasodilator response to adenosine triphosphate-sensitive potassium channel activation is attenuated during desflurane but preserved during sevoflurane anesthesia compared with the conscious state. Anesthesiology. 1998;88:1023-1035.

44. Chen X, Yamakage M, Namiki A. Inhibitory effects of volatile anesthetics on $\mathrm{K}^{+}$and $\mathrm{Cl}^{-}$channel currents in porcine tracheal and bronchial smooth muscle. Anesthesiology. 2002;96:458-466.

45. Fukushima T, Hirasaki A, Jones KA, Warner DO. Halothane and potassium channels in airway smooth muscle. British journal of anaesthesia. 1996;76:847-853.

46. Pabelick CM, Ay B, Prakash YS, Sieck GC. Effects of volatile anesthetics on storeoperated $\mathrm{Ca}^{(2+)}$ influx in airway smooth muscle. Anesthesiology. 2004;101:373-380. 
47. Hoffman WD, Banks SM, Alling DW, et al. Factors that determine the hemodynamic response to inhalation anesthetics. Journal of applied physiology: respiratory, environmental and exercise physiology. 1991;70:2155-2163.

48. Jones RM, Cashman JN, Mant TG. Clinical impressions and cardiorespiratory effects of a new fluorinated inhalation anaesthetic, desflurane (I-653), in volunteers. British journal of anaesthesia. 1990;64:11-15.

49. Dikmen Y, Eminoglu E, Salihoglu Z, Demiroluk S. Pulmonary mechanics during isoflurane, sevoflurane and desflurane anaesthesia. Anaesthesia. 2003;58:745-748.

50. Rabe KF, Hurd S, Anzueto A, et al. Global strategy for the diagnosis, management, and prevention of chronic obstructive pulmonary disease: GOLD executive summary. Am J Respir Crit Care Med. 2007;176:532-555.

51. Dubois AB, Brody AW, Lewis DH, Burgess BF, Jr. Oscillation mechanics of lungs and chest in man. Journal of applied physiology: respiratory, environmental and exercise physiology. 1956;8:587-594.

52. Albright CD, Bondurant S. Some Effects of Respiratory Frequency on Pulmonary Mechanics. The Journal of clinical investigation. 1965;44:1362-1370.

53. Barnas GM, Yoshino K, Loring SH, Mead J. Impedance and relative displacements of relaxed chest wall up to $4 \mathrm{~Hz}$. Journal of applied physiology: respiratory, environmental and exercise physiology. 1987;62:71-81.

54. Hantos Z, Daroczy B, Suki B, Galgoczy G, Csendes T. Forced oscillatory impedance of the respiratory system at low frequencies. Journal of applied physiology: respiratory, environmental and exercise physiology. 1986;60:123-132.

55. Oostveen E, MacLeod D, Lorino H, et al. The forced oscillation technique in clinical practice: methodology, recommendations and future developments. Eur Respir J. 2003;22:1026-1041.

56. Sasaki H, Takishima T, Sasaki T. Influence of lung parenchyma on dynamic bronchial collapsibility of excised dog lungs. Journal of applied physiology: respiratory, environmental and exercise physiology. 1977;42:699-705.

57. Fredberg JJ, Keefe DH, Glass GM, Castile RG, Frantz ID, 3rd. Alveolar pressure nonhomogeneity during small-amplitude high-frequency oscillation. Journal of 
applied physiology: respiratory, environmental and exercise physiology. 1984;57:788800.

58. Hantos Z, Daroczy B, Suki B, Nagy S, Fredberg JJ. Input impedance and peripheral inhomogeneity of dog lungs. Journal of applied physiology: respiratory, environmental and exercise physiology. 1992;72:168-178.

59. Tepper R, Sato J, Suki B, Martin JG, Bates JH. Low-frequency pulmonary impedance in rabbits and its response to inhaled methacholine. Journal of applied physiology: respiratory, environmental and exercise physiology. 1992;73:290-295.

60. Sakae RS, Martins MA, Criado PM, Zin WA, Saldiva PH. In vivo evaluation of airway and pulmonary tissue response to inhaled methacholine in the rat. Journal of applied toxicology : JAT. 1992;12:235-238.

61. Tomioka S, Bates JH, Irvin CG. Airway and tissue mechanics in a murine model of asthma: alveolar capsule vs. forced oscillations. Journal of applied physiology: respiratory, environmental and exercise physiology. 2002;93:263-270.

62. Hildebrandt J. Dynamic properties of air-filled excised cat lung determined by liquid plethysmograph. Journal of applied physiology: respiratory, environmental and exercise physiology. 1969;27:246-250.

63. Hildebrandt J. Pressure-volume data of cat lung interpreted by a plastoelastic, linear viscoelastic model. Journal of applied physiology: respiratory, environmental and exercise physiology. 1970;28:365-372.

64. Suki B, Yuan H, Zhang Q, Lutchen KR. Partitioning of lung tissue response and inhomogeneous airway constriction at the airway opening. Journal of applied physiology: respiratory, environmental and exercise physiology. 1997;82:1349-1359.

65. Fredberg JJ, Stamenovic D. On the imperfect elasticity of lung tissue. Journal of applied physiology: respiratory, environmental and exercise physiology. 1989;67:2408-2419.

66. Bates JHT, Irvin CG, Farré R, Hantos Z. Oscillation Mechanics of the Respiratory System. Comprehensive Physiology. 2011;1.

67. Navajas D, Farre R, Canet J, Rotger M, Sanchis J. Respiratory input impedance in anesthetized paralyzed patients. Journal of applied physiology: respiratory, environmental and exercise physiology. 1990;69:1372-1379. 
68. Hantos Z, Suki B, Csendes T, Daroczy B. Constant-phase modelling of pulmonary tissue impedance. Bull Eur Physiopathol Respir. 1987;23(Suppl. 12.):326s.

69. Hantos Z, Daroczy B, Csendes T, Suki B, Nagy S. Modeling of low-frequency pulmonary impedance in dogs. Journal of applied physiology: respiratory, environmental and exercise physiology. 1990;68:849-860.

70. Petak F, Habre W, Hantos Z, Sly PD, Morel DR. Effects of pulmonary vascular pressures and flow on airway and parenchymal mechanics in isolated rat lungs. Journal of applied physiology: respiratory, environmental and exercise physiology. 2002;92:169-178.

71. Van de Woestijne KP, Franken H, Cauberghs M, Landser F, Clement J. A modification of the forced oscillation technique. In: Advances in Physiological Sciences. Respiration. (Edited by Hutás I and Debreczeni LA.). Proc. of $28^{\text {th }}$ Int. Congr. Physiol. Sci. Budapest, Hungary. June 1980. Pergamon, Oxford, UK. 1981:655-660.

72. Petak F, Hantos Z, Adamicza A, Asztalos T, Sly PD. Methacholine-induced bronchoconstriction in rats: Effects of intravenous vs. aerosol delivery. Journal of applied physiology: respiratory, environmental and exercise physiology. 1997;82:1479-1487.

73. Petak F, Babik B, Hantos Z, et al. Impact of microvascular circulation on peripheral lung stability. Am J Physiol Lung Cell Mol Physiol. 2004;287:L879-889.

74. Sterling GM. The mechanism of bronchoconstriction due to hypocapnia in man. Clin Sci. 1968;34:277-285.

75. Duane SF, Weir EK, Stewart RM, Niewoehner DE. Distal airway responses to changes in oxygen and carbon dioxide tensions. Respiration physiology. 1979;38:303311.

76. Lindeman KS, Croxton TL, Lande B, Hirshman CA. Hypocapnia-induced contraction of porcine airway smooth muscle. Eur Respir J. 1998;12:1046-1052.

77. Lutchen KR, Hantos Z, Petak F, Adamicza A, Suki B. Airway inhomogeneities contribute to apparent lung tissue mechanics during constriction. Journal of applied physiology: respiratory, environmental and exercise physiology. 1996;80:1841-1849. 
78. Nadel JA, Widdicombe JG. Effect of changes in blood gas tensions and carotid sinus pressure on tracheal volume and total lung resistance to airflow. J Physiol. 1962;163:13-33.

79. Parker JC, Peters RM, Barnett TB. Carbon dioxide and the work of breathing. The Journal of clinical investigation. 1963;42:1362-1372.

80. Jammes Y, Davies A, Widdicombe JG. Tracheobronchial and laryngeal responses to hypercapnia, histamine and capsaicin in dogs. Bull Eur Physiopathol Respir. 1985;21:515-520.

81. Sterling GM, Holst PE, Nadel JA. Effect of $\mathrm{CO}_{2}$ and $\mathrm{pH}$ on bronchoconstriction caused by serotonin vs. acetylcholine. Journal of applied physiology: respiratory, environmental and exercise physiology. 1972;32:39-43.

82. Astin TW, Barer GR, Shaw JW, Warren PM. The action of carbon dioxide on constricted airways. J Physiol. 1973;235:607-623.

83. Ferreira JH, Terzi RG, Paschoal IA, Silva WA, Moraes AC, Moreira MM. Mechanisms underlying gas exchange alterations in an experimental model of pulmonary embolism. Brazilian journal of medical and biological research. 2006;39:1197-1204.

84. Vidal Melo MF, Harris RS, Layfield D, Musch G, Venegas JG. Changes in regional ventilation after autologous blood clot pulmonary embolism. Anesthesiology. 2002;97:671-681.

85. Levy SE, Simmons DH. Redistribution of alveolar ventilation following pulmonary thromboembolism in the dog. Journal of applied physiology: respiratory, environmental and exercise physiology. 1974;36:60-68.

86. Simon BA, Tsuzaki K, Venegas JG. Changes in regional lung mechanics and ventilation distribution after unilateral pulmonary artery occlusion. Journal of applied physiology: respiratory, environmental and exercise physiology. 1997;82:882-891.

87. Dantzker DR, Bower JS. Alterations in gas exchange following pulmonary thromboembolism. Chest. 1982;81:495-501.

88. Santolicandro A, Prediletto R, Fornai E, et al. Mechanisms of hypoxemia and hypocapnia in pulmonary embolism. Am J Respir Crit Care Med. 1995;152:336-347. 
89. Brown RH, Wagner EM. Mechanisms of bronchoprotection by anesthetic induction agents: propofol versus ketamine. Anesthesiology. 1999;90:822-828.

90. Jackson AC, Loring SH, Drazen JM. Serial distribution of bronchoconstriction induced by vagal stimulation or histamine. Journal of applied physiology: respiratory, environmental and exercise physiology. 1981;50:1286-1292.

91. Ebert TJ, Muzi M. Sympathetic hyperactivity during desflurane anesthesia in healthy volunteers. A comparison with isoflurane. Anesthesiology. 1993;79:444-453.

92. Goff MJ, Arain SR, Ficke DJ, Uhrich TD, Ebert TJ. Absence of bronchodilation during desflurane anesthesia: a comparison to sevoflurane and thiopental. Anesthesiology. 2000;93:404-408.

93. Eshima RW, Maurer A, King T, et al. A comparison of airway responses during desflurane and sevoflurane administration via a laryngeal mask airway for maintenance of anesthesia. Anesth Analg. 2003;96:701-705, table of contents.

94. Habre W, Petak F, Sly PD, Hantos Z, Morel DR. Protective effects of volatile agents against methacholine-induced bronchoconstriction in rats. Anesthesiology. Feb 2001;94(2):348-353.

95. Mazzeo AJ, Cheng EY, Bosnjak ZJ, Coon RL, Kampine JP. Differential effects of desflurane and halothane on peripheral airway smooth muscle. British journal of anaesthesia. 1996;76:841-846.

96. Mercier FJ, Naline E, Bardou M, et al. Relaxation of proximal and distal isolated human bronchi by halothane, isoflurane and desflurane. Eur Respir J. 2002;20:286292.

97. Park KW, Dai HB, Lowenstein E, Sellke FW. Epithelial dependence of the bronchodilatory effect of sevoflurane and desflurane in rat distal bronchi. Anesth Analg. 1998;86:646-651.

98. Wiklund CU, Lim S, Lindsten U, Lindahl SG. Relaxation by sevoflurane, desflurane and halothane in the isolated guinea-pig trachea via inhibition of cholinergic neurotransmission. British journal of anaesthesia. 1999;83:422-429.

99. Wiklund CU, Lindsten U, Lim S, Lindahl SG. Interactions of volatile anesthetics with cholinergic, tachykinin, and leukotriene mechanisms in isolated Guinea pig bronchial smooth muscle. Anesth Analg. 2002;95:1650-1655, table of contents. 
100. Brichant JF, Gunst SJ, Warner DO, Rehder K. Halothane, enflurane, and isoflurane depress the peripheral vagal motor pathway in isolated canine tracheal smooth muscle. Anesthesiology. 1991;74:325-332.

101. Vettermann J, Warner DO, Brichant JF, Rehder K. Halothane decreases both tissue and airway resistances in excised canine lungs. Journal of applied physiology: respiratory, environmental and exercise physiology. 1989;66:2698-2703.

102. Brown RH, Zerhouni EA, Hirshman CA. Comparison of low concentrations of halothane and isoflurane as bronchodilators. Anesthesiology. 1993;78:1097-1101.

103. Ishikawa T, Shinozuka N, Sato J, Nishino T. Inhalation anaesthetics produce asynchronous reversal of ventilation inhomogeneity and increased lung resistance in a canine model of bronchial asthma. British journal of anaesthesia. 1998;80:807-813.

104. Katoh T, Ikeda K. A comparison of sevoflurane with halothane, enflurane, and isoflurane on bronchoconstriction caused by histamine. Can J Anaesth. 1994;41:12141219.

105. Mitsuhata H, Saitoh J, Shimizu R, Takeuchi H, Hasome N, Horiguchi Y. Sevoflurane and isoflurane protect against bronchospasm in dogs. Anesthesiology. 1994;81:12301234. 